
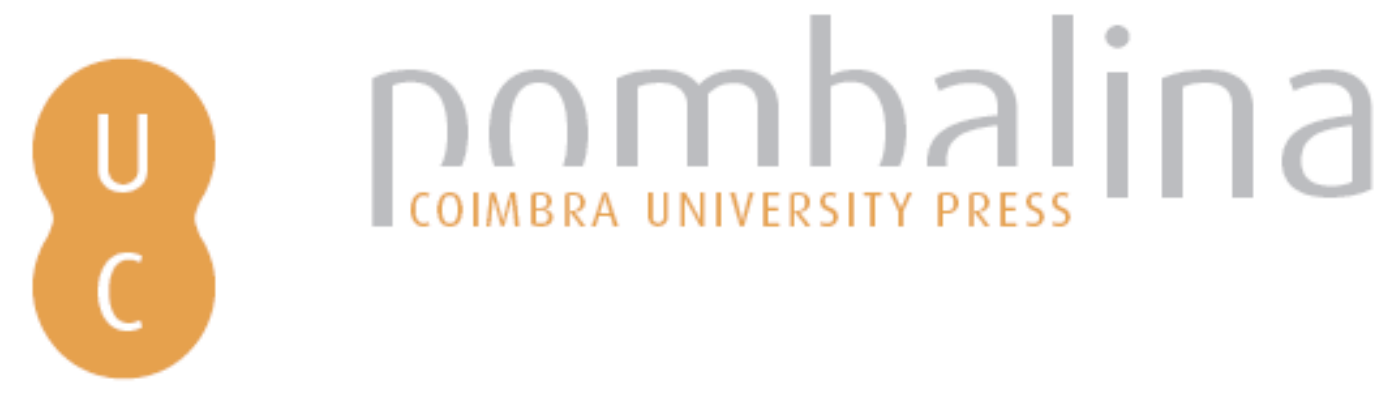

\title{
"Selecionando crepúsculos": a função dos clássicos na concepção de cultura e civilização de Luis da Câmara Cascudo
}
Autor(es):
Augusto, Maria das Graças de Moraes
Publicado por: Imprensa da Universidade de Coimbra; Annablume
URL
persistente:
URI:http://hdl.handle.net/10316.2/40828
DOI:
DOI:https://doi.org/10.14195/978-989-26-1280-5_13
Accessed : $\quad$ 26-Apr-2023 11:57:55

A navegação consulta e descarregamento dos títulos inseridos nas Bibliotecas Digitais UC Digitalis, UC Pombalina e UC Impactum, pressupõem a aceitação plena e sem reservas dos Termos e Condições de Uso destas Bibliotecas Digitais, disponíveis em https://digitalis.uc.pt/pt-pt/termos.

Conforme exposto nos referidos Termos e Condições de Uso, o descarregamento de títulos de acesso restrito requer uma licença válida de autorização devendo o utilizador aceder ao(s) documento(s) a partir de um endereço de IP da instituição detentora da supramencionada licença.

Ao utilizador é apenas permitido o descarregamento para uso pessoal, pelo que o emprego do(s) título(s) descarregado(s) para outro fim, designadamente comercial, carece de autorização do respetivo autor ou editor da obra.

Na medida em que todas as obras da UC Digitalis se encontram protegidas pelo Código do Direito de Autor e Direitos Conexos e demais legislação aplicável, toda a cópia, parcial ou total, deste documento, nos casos em que é legalmente admitida, deverá conter ou fazer-se acompanhar por este aviso.

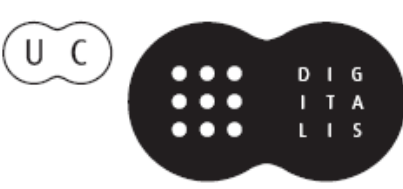




\section{Pólis/Cosmópolis}

\section{Identidades Globais \& Locais}

Carmen Soares, Maria do Céu Fialho \& Thomas Figueira (coords.)

IMPRENSA DA UNIVERSIDADE DE COIMBRA 


\title{
"SElEcionando CREPÚSCULOS": \\ A FUNÇÃo DOS CLÁSSICOS NA CONCEPÇÃO DE CULTURA E civilização de Luis da CÂmara Cascudo. \\ ("Selecting Twilights": the Function of the Classics in Luis da Câmara Cascudo's Conception of Culture and Civilization)
}

\author{
Maria das Graças de Moraes Augusto (mgmaugusto@yahoo.com.br) \\ Universidade Federal do Rio de Janeiro
}

\begin{abstract}
Resumo - Luis da Câmara Cascudo foi um dos intérpretes mais argutos dos diferentes níveis em que a "cultura" e a "civilização" se estabelecem no âmbito das "tradições brasileiras". Nesse sentido, estudou o folclore, a literatura oral, os gestos, as narrativas, a geografia dos mitos, os hábitos, os ritos e os cultos, os alimentos e as bebidas, e em todos esses estudos encontramos as marcas da tradição clássica tanto como ponto de partida ou mesmo como ponto de chegada de suas análises, pois, como sublinhou em diferentes ocasiões, "a literatura clássica me preservou da tirania das idéias".

Partindo da assertiva acima, o objetivo de nosso trabalho é mostrar como, na obra de Câmara Cascudo e em sua estrutura hermenêutica de nossas tradições, a cultura greco-romana é um dos elementos formadores para a compreensão da "cultura" e da "civilização" brasileiras.

Palavras-chave: Tradição Clássica no Brasil. Civilização e Cultura. Mito e folclore.
\end{abstract}

Abstract - Luis da Câmara Cascudo was one of the most astute interpreters of the different levels at which "culture" and "civilization" were organized within the scope of "Brazilian traditions". In this sense, he studied folklore, oral literature, gestures, narratives, the geography of myths, habits, rites and cults, and food and beverages. In all these studies, it is possible to find the marks of the classical tradition both as a starting point and as a culmination of this analysis, because, as he pointed out on several occasions, "classic literature protected me from the tyranny of ideas".

Starting from the above-mentioned statement, the aim of my paper is to show how, in the work of Câmara Cascudo and in the hermeneutic structure of our traditions, Greco-Roman culture is one of the formative elements required to understand Brazilian "culture" and "civilization".

Keywords: Classical Tradition, Brazil, Civilization, Culture, Myth, Folklore

"Já a leste uma levíssima névoa azulada crepusculizava as linhas distantes." D. João de Castro, Jornadas no Minho, p. 268.

"No day of my life passes now to its sunset, without leaving me more doubtful of all our cherished contempts, and more earnest to discover what root there was for the stories of good men, which are now the mocker's treasure." Ruskin, J. St. Mark's rest. The shrine of the slaves, p. 17. 
No conjunto das "cascudianas", pequenas histórias que evidenciam o "bom humor" de Luis da Câmara Cascudo, recolhidas por Diógenes da Cunha Lima, encontramos a reprodução de um diálogo entre ele e o então governador do Rio Grande do Norte, Sylvio Pedroza, que, acostumado a ir ter com ele ao final do expediente no Palácio Potengi, reclama por não mais encontrá-lo:

“- Que aconteceu, Cascudo? No fim do expediente não o encontro em casa. Não o vejo mais.

- Estou selecionando crepúsculos. Toda tarde, cinco e meia, saio de casa e vou ver o crepúsculo de um ângulo novo. Não é pra nada, só alegria íntima."

Ora, se, tal como fazia o próprio Cascudo quando investigava ou citava a obra e as idéias de um pensador, começarmos pela identificação de sua data de nascimento e morte, verificaremos que Luis da Câmara Cascudo nasceu na cidade do Natal, em 30 de dezembro 1898 e aí faleceu em 30 de julho de 1986. Isto significa que sua vida transcorre entre o final do século XIX e o penúltimo decênio do século $\mathrm{XX}$, portanto, um homem entre dois mundos, ou, talvez, um homem que viu esses dois mundos em sua dupla dimensão crepuscular, a matutina e a vespetina:

"Ôrai, Hora, Horae, Horas, as três estações gregas, vinte e quatro horas do dia e da noite, filhas de Cronus, o Tempo, sempre tiveram respeito para o espírito dos homens de outrora. Dividiam a luz e as trevas com as gradações de penumbra. Assistiam aos mistérios, aos encantamentos, ao nascer e morrer de todas as coisas deste mundo. Tudo em sua hora! ... Boa hora, má hora, são os quadros normais da atividade humana. Vinte séculos caíram sobre as devoções greco-romanas às Ôrai mas os vestígios resistiram e são reconhecíveis nos dias contemporâneos. (...)

O grego inventou o mito de Alectrion, o companheiro de Marte, encarregado de vigiar e guardar os seus encontros com a deusa Vênus. Alectrion descuidou-se e o Sol avistou os dois amantes, indo denunciá-los a Vulcano, marido enganado. Por isso o galo canta estridentemente durante a noite, anunciando a aproximação do Sol, lembrando do castigo e da perdida dignidade custodial. O canto do galo é a divisão mais universal. Dividia a noite grega e passou para Roma. Para os romanos noctis septem tempora sunt. Eram os crepusculum, Fax, quando as luzes se acendiam; concubium, hora de dormir, quo nos quieti damus, a noite alta, nox intempesta, seguindo-se o gallicinium, quando o galo canta, e conticinium, quando ele cessa o canto, finalmente aurora, tempus quod ante solem est. Literariamente dizem antelecucem, quando a manhã bruxuoleia, ad

\footnotetext{
${ }^{1}$ Cf. Lima, 1998:175.
} 
"Selecionando crepúsculos": a função dos clássicos na concepção de cultura e civilização de Luis da Câmara Cascudo

meridiem, meridiem, perto do meio-dia e meio-dia etc. (...)

No tocante às supertições diz-se em Portugal horas abertas, horas sem defesas, tempo em que as forças do Mal estão livres de reação maior, aos quatro períodos do dia, Meio-Dia, Meia-Noite e os crepúsculos vespertino e matutino. Surgem nessas horas os fantasmas, animais encantados, pavores, formas assombrosas e vagas que o canto do galo dissipa. Nos crepúsculos portugueses passam a galinha com os pintos, a porca dos sete leitões, a ovelha, a moura, o tardo, o coisa-ruim, a zorra de Odeloca berrando. (...)

No sertão rezam as velhas senhoras pela madrugada, quando os galos amiúdam os cantos. Há horas melhores para Deus escutar o pedido. Antes do sol nascer, com sinais-de-dia no horizonte, as rezas são de efeito prodigioso. Mantém-se a tradição de orar com velas acesas, (...). A muita luz dispersa a atenção e a penumbra concentra o pensamento.

A Morte prefere visitar os doentes nessas horas abertas, especialmente nos dois crepúsculos. Quando o Sol nasce ou morre são as horas-da-Morte. ${ }^{2}$

A reflexão sobre as Ôrai no ensaio XVI, do famoso Anúbis e outros ensaios, no qual os temas de nossa "mitologia" são recenseados em seu passado mais remoto, onde a literatura clássica é fonte constante de informação e recurso hermenêutico para uma avaliação das matrizes temporais de nossas tradições, a explicitação da função crepuscular, os crepúsculos matutinos e vespertinos, já nos oferece um quadro valioso dos limites, dos temas e das ambições da investigação cascudiana: a "civilização" e a "cultura"; a morfologia das "coisas do povo" e das "coisas da ciência”, expressas pela determinação das atividades humanas no intervalo crepuscular, tanto no nível das crenças quanto no nível do determinismo das "ciências iátricas". ${ }^{3}$

Por outro lado, a angulosidade nova de cada crepúsculo selecionado por Cascudo parece apontar não somente para a dupla formação intelectual de "nosso etnógrafo": a medicina, que estudou até o 4o. ano, primeiro na Faculdade de Medicina da Bahia, em 1918, e depois na Faculdade de Medicina Rio de Janeiro, de 1919 a 1922, e, o direito cursado na Escola do Recife de 1924 a 1928, ${ }^{4}$ quando concluiu o bacharelado, mas, sobretudo, para a função que exerceu ao longa de toda a sua vida, a de professor. ${ }^{5}$

${ }^{2}$ Cascudo, 1983, 2a: 117-120.

${ }^{3}$ Ver também, Cascudo, 1983: 611: “Ainda o povo de Portugal e Brasil aceitará a presença tenebrosa das horas abertas, em que a moléstia é mais traiçoeira e a Morte mais freqüente. Horas dos crepúsculos matutino e vespertino, hora em que se morre, coincidente com os abaixamentos de temperatura, descompressão, desequilíbrios climático. (...). O determinismo que as ciências iátricas pretendiam impor ao organismo humano é irmão da ditadura endocrínica ou do fatalismo biotipológico."

${ }^{4}$ Gico, 1998: 7-18.

${ }^{5}$ Luis da Câmara Cascudo foi professor da Escola Normal, do Colégio Atheneu Norte-

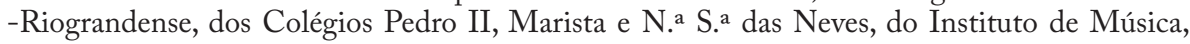


Foi como professor que Cascudo escreveu grande parte de sua obra e conduziu suas pesquisas "além das limitações dos currículos" tal como expõe na Preliminar de Civilização e Cultura,

"Já as fogueiras de São João seis vezes foram acesas desde que comecei este livro. E seis vezes ouvi a missa-do- galo na noite de Natal. Trabalho em dezembro, quando os cursos estão encerrados e eu posso viajar na quarta dimensão das simpatias bibliográficas, além das limitações dos currículos.

Naturalmente não compendiei a matéria de etnografia geral talqualmente exponho aos meus alunos da Faculdade de Filosofia, e sim reuni documentário sobre os vários ângulos de possível curiosidade, finalizando o programa total."”

Assim, acreditamos, será o valor reflexivo que a metáfora da seleção de crepúsculos indicar-nos-á na aparente 'brincadeira' bem humorada da história contada por Diógenes da Cunha Lima, o crepúsculo evoca vários níveis da investigação cascudiana, expressando a busca de algo cuja duração se repete na pluralidade das horas, mas que, para ser visto, exige acuidade de visão para valer-se, como método de trabalho, da penumbra propiciadora da concentração do pensamento, capaz de demarcar uma "ação criadora" que emerge dos inconciliáveis fim e começo, fluxo e refluxo, como uma "contemporaneidade do milênio, o presente da 'antiguidade', as formas vivas na diuturnidade do exemplo."” A busca das "constantes etnográficas" serão agenciadas a partir de uma rotina de trabalho que levou-o a ler a literatura grega e latina, pois, nelas, descobria, conforme contou a Zila Mamede, que "a farinha de peixe da Amazônia era conhecida dos babilônios; que o costume de estirar a língua já fora anotada em Tito Lívio, supertições ouvidas na cozinha doméstica estavam em Horácio, Tácito e Suetônio, em Aristótles e Xenofonte."

Portanto, o que pretendo discutir aqui, nesse curto tempo confenrencial, são as grandes linhas interpretativas contidas na imensa obra de Luis da Câmara Cascudo, que nos remetem a uma hermenêutica original, mas não solitária, porque no mesmo lastro podemos divisar autores como João Guimarães Rosa, Manuel Bandeira, Gilberto Freyre e Sérgio Buarque de Hollanda, no contexto do pensamento brasileiro do século XX: uma leitura do Brasil à luz de uma certa concepção de 'civilização' e de 'cultura', na qual viajam os elementos mas não o

e, Professor Emérito da Universidade Federal do Rio Grande do Norte, da qual foi um dos fundadores, e onde ensinou Direito Internacional, na Faculdade de Direito e Etnografia, na Faculdade de Filosofia. Na UFRN, Cascudo foi diretor do Instituto de Antropologia, onde funciona, atualmente, o Museu Câmara Cascudo. Cf. Gico, op. cit., p.7 e a nota da Editora Itatiaia com os dados biográficos do autor, na edição de 1983, de Cultura e Civilização.

${ }^{6}$ Cascudo,1983: 15. Grifo nosso.

${ }^{7}$ Cascudo, 1983: 693.

${ }^{8}$ Mamede, 1970: 12, v.1. 
corpo da civilização determinante. ${ }^{9}$ Para tanto, vou dividir esta apresentação tomando por base duas obras de Câmara Cascudo: a basilar Civilização e Cultura, e o confessional Prelúdio e fuga do real, desconhecido, creio, de boa parte dos intérpretes do pensamento brasileiro do século passado.

\section{Civilização e Cultura: o presente da "antiguidade”}

A publicação dos dois volumes de Civilização e Cultura - Pesquisas e notas de Etnografia geral, pela Livraria José Olympio Editora, em 1973, foi o fim de um conturbado percurso editorial. Segundo nos conta Cascudo, em "História de um livro perdido", separata dos Arquivos do Instituto de Antropologia da UFRN, publicada em junho de $1966,{ }^{10}$ durante dez anos ele trabalhou intensamente na elaboração da obra, e uma vez concluído o trabalho, o original foi entregue à Imprensa Estadual de Pernambuco, por convite de "afetuoso amigo". Com a demora na publicação do trabalho, Cascudo foi instado, em dezembro de 1964, por Zeferino Vaz, então reitor da Universidade de Brasília e pelos professores Onofre Lopes e José Tavares da Silva, da UFRN, a transferir a edição da obra para uma coleção brasileira de divulgação científica que Vaz pretendia inaugurar em Brasília. Foi quando, então, telegrafou a Recife solicitando a devolução dos originais, e, para sua indignada surpresa, descobriu que o livro, do qual não tinha cópia, havia desaparecido, restando apenas o "título melancólico de livro perdido"11. Dos originais desaparecidos apenas três capítulos já haviam sido publicados ${ }^{12}$, e dada a impossibilidade de "reavivar o roteiro das pesquisas, análises e conclusões, nem sempre maquinais dos cursos na Etnografia Geral" ${ }^{13}$, a divulgação do Índice geral e do Índice de assuntos, que com algumas notas esparsas, constituíam o saldo total do esforço de todos aqueles anos, visava resgistar e comprovar os temas estudados e investigados direta e indiretamente, em viagem e livro, em uma "simples indicação denominadora, desde que o texto não existe mais." ${ }^{14}$

Quatro anos depois os originais reapareceram e foram devolvidos "amarrotados como papel de embrulho, sujos, riscados, alguns capítulos incompletos, páginas e páginas inutilizadas por um delírio neurótico de riscos e interrogações! O livro perdido passara a Livro Morto. Guardei-o numa gaveta para todo o sempre." ${ }^{15}$ Entretanto, com a intervenção de Daniel Pereira, diretor da José Olympio, "pretendendo reaver o defunto", e a ação efetiva de Onofre Lopes, em

\footnotetext{
${ }^{9}$ Cf. Cascudo, 1983: 17-21.

${ }^{10}$ Cascudo, 1966: 5-19.

${ }^{11}$ Cascudo, 1966: 5.

${ }^{12}$ Idem, ibidem.

${ }^{13}$ Idem, ibidem.

${ }^{14}$ Cascudo, 1966: 6.

${ }^{15}$ Cascudo, 1983: 23.
} 
maio de 1971, desejando a publicação do livro tal como "estivesse no arquivo, sem prever prêmio ou recompensa, para documentar o labor desinteressado e tenaz, dos professores provincianos do Brasil Universitário", e uma vez que, em 1963, a Etnografia Geral havia sido suprimida do currículo da ex-Faculdade de Filosofia, o que equivalia, segundo Cascudo, a ensinar álgebra sem aritmética ou a "semear no mar", como suspirara Bolívar, ele decide por sua publicação, concluindo, assim, a "odisséia de sua tarefa" com o ressarcimento das "melancolias de onze anos angustiados." ${ }^{16}$

As 741 páginas que compõem o texto estão estruturadas em três eixos centrais: [i] a questão histórica, isto é, a apresentação das diversas tentativas de conceitualização da antropologia como disciplina e dos sentidos aí atribuídos à etnografia e à etnologia, desde a etimologia até ao contexto "evolutivo" de suas teorias e doutrinas; [ii] a determinação de uma teoria da cultura e da civilização que conforma a determinação dos "elementos da estabilidade humana"; e, [iii] a descrição de cada um desses elementos: a ecologia, o instinto aquisitivo, a conduta e a norma, o fogo, o abrigo, o agasalho, a ornamentação, as jóias, o cabelo, a barba, o bigode, o corpo humano como medida do mundo, as funções físicas e simbólicas, o senso de orientação, o primeiro lar, a propriedade, a caça, a pesca, a domesticação de animais, a agricultura, a alimentação, o comércio, os transportes, o solidarismo, a economia e as indústrias milenarias, a religião, a antropofagia, a arte, a lúdica, a dança, os instrumentos sonoros, o canto, a poesia, o teatro, os esportes, a medicina, a fala, a escrita e o poder do nome, a família, o governo, a lei, a delegação e o direito, e, a cultura popular; a partir de uma exaustiva exemplificação do que Cascudo chamará de "constantes etnográficas", obtidas pela confluência de dados e informações que atravessam distancias geográficas e culturais como uma "ação criadora". ${ }^{17}$

Avesso às questões de método, o que por mais de uma vez será sublinhado em Civilização e cultura,

"Não me alistando sob qualquer bandeira doutrinária, e tendo para os mestres uma admiração fervorosa que não implica submissão deslumbrada nem preito de obediência, tive nessa etnografia geral a mesma curiosidade de percurso com que viajei pelo mundo, sem guias letrados e sem itinerários marcados pelo asterisco do Baedeker. Fui procurando com a simples alegria da identificação e a todos ouvindo sem a obrigatoriedade devocional.

Não me arrependo da ausência de métodos e menos ainda de ter recorrido aos elementos que julgo úteis para um esclarecimento,"18

\footnotetext{
${ }^{16}$ Cascudo, 1983: 24.

${ }^{17}$ Cascudo, 1983: 17.

${ }^{18}$ Cascudo, 1983: 15.
} 
e seguidor ativo da máxima machadiana de que a epígrafe "não é somente um meio de complementar as pessoas da narração com as idéias que deixarem, mas ainda um par de lunetas para que o leitor do livro penetre o que for menos claro ou totalmente escuro" ${ }^{19}$, Cascudo aporá como epígrafe às 741 páginas de Civilização e cultura, a passagem dos Atos dos Apóstolos, IV, 20: "Não podemos, pois, deixar de falar das coisas que temos visto e ouvido", para marcar toda sua tarefa etnográfica, isto é, a exposição de motivos e argumentos sem o sentido da decisão doutrinária, de modo sempre provisório, atendo-se ao caminho como uma conseqüência natural da própria percepção do conjunto. ${ }^{20}$

É nesse 'caminho' que a Antiguidade Clássica parece subsidiar boa parte dos argumentos e dos motivos que irão possibilitando essa 'percepção do conjunto', e, é pois, buscando trilhar esse caminho que tentarei delinear os temas clássicos nos argumentos cascudianos.

\footnotetext{
${ }^{19}$ Machado de Assis, 1970: 966.

${ }^{20}$ Cascudo, 1983: 21.
} 


\subsection{A parte é maior do que o todo?}

Ao afirmar, logo no começo de suas análises que o objeto de estudo da etnografia é a origem e estabelecimento, modificações e vitalidade das culturas humanas e que, por isso, tudo o que interessa ao homem no plano da temporalidade tem raiz etnográfica, constituindo uma "memória no tempo":

"A simpatia natural pela etnografia é que ela evoca documentadamente a história de nossa grande família humana, evidenciando continuidades e seqüências que orgulham ou decepcionam. (...).

E nota-se que o passado imemorial não desapareceu de todo, e deparamos as sombras milenárias nos gestos diários e às vezes no mecanismo do raciocínio, para a soma surpreendente de soluções psicológicas.

Um ato comum e banal pode ter cinqüenta séculos (...). E tudo vive em nós, herdeiros de gerações incontáveis e sucessivas.

Por isso a etnografia é sedutora. É a nossa memória no tempo! ...”21,

Câmara Cascudo, ver-se-á frente à necessidade de diferenciar Civilização e cultura para que o objeto da etnografia possa ser corretamente delineado: "civilização é todo e cultura é parte". ${ }^{22}$

A civilização será, então, o conjunto das culturas, o elemento que lhe dá caráter, coloração, a peculiaridade do nacional; a cultura é a parte sem o espírito do todo no tempo e no espaço, e a cultura geral de um país é a sua civilização, é "um órgão indispensável no corpo mas não é o corpo e menos o espírito unificador e orgânico. Civilização não se exporta, arrenda, empresta, compra, imita. Essa é a característica das culturas. A cultura emigra e a civilização é sedentária, estática quanto à permanência no âmbito sócio-geográfico.

Por isso, dirá Cascudo,

“a cultura é um exercício aplicado a um esforço para finalidade determinada e única. Nunca o geral, o conjunto, a totalidade. É um músculo, um órgão, um nervo. Jamais o organismo inteiro. Um rio, uma árvore, uma montanha. Não a paisagem completa", ${ }^{23}$

e será nesse sentido movente e perseverante do patrimônio tradicional de normas, doutrinas, hábitos, acúmulo do material herdado e acrescido pelas aportações inventivas de cada geração que ele sublinhará o "encanto heróico da etnografia" ao fazer findar "a imagem rutilante da civilização única que deve ser a mesma em todo o mundo e quem não lhe pertencer está condenado a selvageria. A lição,

\footnotetext{
${ }^{21}$ Cascudo, 1983: 27.

${ }^{22}$ Cascudo, 1983: 17.

${ }^{23}$ Cascudo, 1983: 39.
} 
dirá ainda, nem por todos percebida, é que cada povo organizará a sua civilização e que as culturas constituintes devem ser livremente escolhidas, mantidas ou criadas na mentalidade nacional reajustadora. Padronização! Voilà l'ennemi .... ${ }^{24}$

Assim, a discussão das relações entre a parte e o todo, tomada como mediadora da teoria e do ofício etnográficos, parece estar atrelada ao velho contexto grego exposto, por exemplo, nos Trabalhos e Dias de Hesíodo, e feito método e princípio nas doutrinas da medicina hipocrática, para falarmos em autores clássicos citados e epigrafados por Cascudo em vários momentos da discussão em Civilização e cultura, e que já estava perfeitamente delineada no texto de abertura da obra intitulado "Preliminar" quando elenca os antigos clássicos no contexto de sua investigação:

"Não é novidade encontrarem-se em Terêncio, Virgílio, Horácio, Cícero, Aristófanes, Hesíodo, o infinito Homero, nos trágicos, epigramistas gregos, eróticos, votivos, funerários e descritivos, elementos elucidadores da vida cotidiana da Grécia e Roma não registados noutras paragens. Um pormenor que não está em Estrabão vive numa comédia de Plauto. Ausente em Diodoro da Sićlila mas presente no Satyricon de Petrônio. Não consta em Denis de Halicarnasso mas Luciano de Samosata anotou. Para certos momentos da história social, da normalidade romana, são indispensáveis Juvenal, Ovídio, Marcial, Tíbulo, Propércio, Catulo, Lucrécio, Sêneca, Lucano. Por que não aproveita-los mesmo retirando-os do mostruário alheio? Aparecem comumente com notícias que eles viram e viveram.

Um objeto prova sua existência surgindo num rol do linear B de Cnossos ou numa sátira de Pérsio.”. ${ }^{25}$

Nesse sentido, a cultura será a seguir estudada em todos os seus aspectos, das questões teóricas relativas a sua origem, sua conformação primeva, os usos do ouro, prata, cobre, bronze e ferro, as relações entre pré-história e proto-história e os processos de aculturação e miscigenização, para só, então, introduzir a análise dos elementos da estabilidade humana. Em toda a discussão acerca da formação da cultura a presença do "infinito Homero", de Hesíodo e Heródoto, Virgílio, Ovídio e Tácito, serão exemplares no auxílio compreensivo das questões mencionadas acima, cuja análise proponho deixarmos para uma outra oportunidade, de modo a podermos passar para o segundo item de nossa recensão temática, contido no contexto dos elementos da estabilidade humana que serão denominadas por Camara Cascudo, na mesma obra, de "formas vivas na diuturnidade do exemplo".

\footnotetext{
${ }^{24}$ Cascudo, 1983: 42.

${ }^{25}$ Cascudo, 1983: 20. Grifo nosso.
} 
1.2 Os elementos da estabilidade humana e as formas pretéritas vivas na diuturnidade do exemplo

Os elementos da estabilidade humana serão definidos por Câmara Cascudo como provenientes do "instituto gregário" do homem e de sua disposição para uma "convergência fatal" de atração pelo semelhante, e são decorrentes da conquista de uma economia sucessiva e do uso consciente das primeiras técnicas aquisitivas ou simplificadoras da tarefa diária, indispensável, normal e regular. ${ }^{26}$

O primeiro desses elementos, a ecologia, será objeto da crítica de Cascudo de modo a mostrar que o cultural é mais definidor do homem do que o meio ambiente, que o fator humano é que é decisivo, e criticando Hipócrates pela defesa da "quase onipotência geográfica" ${ }^{27}$, exemplificará sua tese com a história do ovo enviado de Natal, em 1933, para a Alemanha, e do qual nasceu um galo, alemão pelo jus soli e brasileiro pelo jus sanguinis, e que ao longo dos seus 5 anos de vida cantou unicamente no horário dos galos do Brasil que ele jamais ouvira: "não houve meio do galo potiguar assimilar o ritmo pregoeiro dos colegas renanos. Manteve a diferença das quatro horas distantes para as doze locais. Levara $a b$ ovo, não apenas o canto mais também a regra imutável dos momentos em que devia cantar. Ecologia alemã inoperante."

O exemplo acima aponta para toda uma concepção da relatividade do tempo cultural que permite que o "antigo" seja presente e permeie o que Cascudo chamou de "contemporaneidade do milênio". Essa contemporaneidade será mostrada na análise de cada um dos elementos estudados, quase sempre com formas pretéritas da Antiguidade Clássica, e aqui vou retomar apenas uma dessas análises, a relativa à 'cultura popular' dada sua vitalidade e importância na inquietação investigativa de nosso autor.

O povo, dirá ele, tem uma cultura que recebeu dos antepassados através do exercício de atos práticos e audição de regras de conduta, religiosa e social, e faz parte de uma camada terciária anteposta aos conhecimentos escolares, transmitidos como ciência indispensável e geral pelo livro e pela voz do ensino magistral. Os dois extratos acompanham a vida normal do homem, existindo entre eles uma intercomunicação viva porque estão no mesmo organismo, tal como dois gêmeos divinos coexistindo na mentalidade humana, disputando o domínio soberano da decisão psicológica: os dióscuros serão, pois, o modelo de toda a concepção cascudiana de cultura popular: "Castor humano e Pólux imortal irmanizam-se na mesma constelação rutilante do conhecimento. Esses dióscuros são a Cultura Popular e a Cultura Letrada, ministrada sob os auspícios das normas oficiais, hierárquicas, rituais. Non adversa, sed diversa." ${ }^{28}$

\footnotetext{
${ }^{26}$ Cascudo, 1983: 147.

${ }^{27}$ Cascudo, 1983: 153.

${ }^{28}$ Cascudo 1983: 680.
} 
"Selecionando crepúsculos": a função dos clássicos na concepção de cultura e civilização de Luis da Câmara Cascudo

A análise pautada hermeneuticamente na história dos dióscuros trará também outros elementos que denotam a vitalidade do pensamento antigo na reflexão cascudiana: a função da memória como reminiscência, como fonte do conhecimento:

"A orelha era dedicada a MNEMOSINE, DEUSA DA MEMÓRIA, mãe das nove Musas. A Fé e a Ciência, no plano do Conhecimento, entravam pela audição. Os velhos Mestres puxavam o pavilhão auricular aos estudantes para que decorassem ou não esquecessem quanto aprendiam nas aulas. Processos de mnemotécnica. Valia castigo, excitando a retentiva dos alunos desatentos ou vadios. Quando alguém puxa a própria orelha, pune-se de não haver ouvido a voz da Razão em tempo oportuno. É o gesto simbólico do Arrependimento. $\mathrm{Na}$ Romagem dos Agravados de Gil Vicente (1533), a vendedora de peixe Maria do Prado, lastima-se: Se tu não deras à golhelha, / Nunca o nosso agravo fora,/ Nem eu torcera a orelha.

'Dar a golhelha' era falar demasiado imprudentemente. Assim, puxar a orelha, significa "lembre-se". Torcê-la, vale confessar, "pequei"! Em Siracusa, Apolo Cintio belisca, vellit, de vellicatio, a orelha do pastor Titiro: (Virgílio, Égogla,VI-3)." ${ }^{29}$

e a eficácia da imitação, da mímesis, em detrimento da imaginação, na preservação da cultura:

"Mas não existe Civilização original e isenta de interdependência, distantes ou próximas, e já constitui dogma etnográfico ensinar-se a pobreza e raridade da imaginação humana e a prestigiosa ascendência da Imitação como processo inevitável normal de ampliação técnica. A cultura é transmitida pelo replantio de galhos floridos e não pelas sementes unitárias. (...) Nesse rumo da Imitação estará a força radicular do instinto aquisitivo, de impressionante persitências." ${ }^{30}$

Assim, o valor da memória e da mímesis na mecânica aculturativa é uma forma de permanência das formas pretéritas que "vêm de longe e agitam as chamas que não mudam de lugar”:

No Fedro, de Platão, conta Sócrates que o deus egípcio Toth encarece ao rei Thamus o uso da escrita e o soberano recusa porque a fixação do acontecimento dispensará no povo o exercício da memória. A sabedoria vive mais ardente na consciência e não nos registos que a sepultam para uma consulta, que é uma breve ressureição. (...) Entre o povo a inteligência aquisitiva e o conhecimento

\footnotetext{
${ }^{29}$ Cascudo 1987.

${ }^{30}$ Cascudo 1983: 682.
} 
fazem um en kaipan, um todo, perpetuamente ao alcance de todos, à luz do sol e das estrelas. A mobilidade da comunicação oral que, aparentemente, seria um processo dispersivo e tumultuoso de esquecimento, é uma forma plástica mas indeformável de conservação e continuidade. A evaporação e perda de certos motivos residem na fraca densidade do interesse e seu desaparecimento não prejudica o restante conteúdo residual, parcialmente renovado na dinâmica dos elementos convergentes e assimilados. ${ }^{{ }^{31}}$

O que seriam essas formas pretéritas que vêm de longe mas não mudam de lugar? Uma variante das idéias platônicas no contexto da etnografia cascudiana?

Deixando a vocês a resposta e a discussão acerca da legitimidade da pergunta, vou passar agora para o segundo texto, Prelúdio e fuga do Real, onde os antigos refluem de sua função de fundamentação teórica e passam a ser personagens de um diálogo com o nosso "professor de província".

\section{A ALMA QUE PENSA: IMORTALIDADE E CONTEMPORANEIDADE}

Prelúdio e fuga do real é uma obra na qual a influência platônica parece decisiva, seja nos aspectos formais, seja na dimensão conteudística das conversas de Luis da Câmara Cascudo com 33 interlocutores, considerados por ele decisivos no âmbito da contemporaneidade do milênio, em um argumento exemplar: a imortalidade da alma. ${ }^{32}$

Como já vimos anteriormente, Câmara Cascudo foi leitor assíduo da literatura clássica, que, como gostava dizer, o tinha imunizado contra a tirania das idéias, e a presença dos diálogos platônicos pode ser vista desde suas citações nominais, mas, também, na menção indireta interlineada à exposição do argumento. No texto que nos detemos agora as menções explícitas são muitas, mas as interlineadas são essenciais para encontrarmos os parâmetros nos quais República e Fédon são modelo de reflexão.

O texto, configurado como um diálogo entre o velho professor e uma interlocutora anônima a quem ele expõe seus temas maiores, a contemporaneidade dos deuses e a imortalidade da alma, e valendo-se da mímesis compõe 34 diálogos com os homens que marcaram a vida intelectual da humanidade, em circunstancias geográficas, antropológicas e sociais distintas daquelas em que, historicamente, eles viveram.

Por outro lado, os dois termos que compõem o título, prelúdio e fuga do real, podem ser entendidos como variantes de dois grandes temas platônicos expostos na República, o proêmio, traduzido aqui por prelúdio, e a habilidade narrativa de fabricar, dialogicamente, com o lógos, uma pólis e uma politeía onde quase todos

\footnotetext{
${ }^{31}$ Cascudo 1983: 686.

${ }^{32}$ Cascudo 1974.
} 
"Selecionando crepúsculos": a função dos clássicos na concepção de cultura e civilização de Luis da Câmara Cascudo

os "elementos da estabilidade humana" estão mimeticamente descritos através da "fuga" para a pluralidade temporal e social.

Por sua vez, o título do prelúdio é já significativo anúncio do valor dialógico da cultura: "Não abaneis a cabeça!", foi retirado do artigo de Machado de Assis, publicado em $A$ Semana, no Rio de Janeiro, em 22 de novembro de 1898, indicação crepuscular e referência dupla à ironia socrática e machadiana, e também, à regra mais fundamental que nortea a vida intelectual de Câmara Cascudo.

Nesse sentido, o prelúdio será um decálogo de sua vida intelectual, expressando os grandes temas de sua obra:

[i] a contemporaneidade dos deuses,

"Não, Madame, não creio que os deuses hajam morrido com a vitória do cristianismo, como a senhora leu em Flaubert. (...) Os deuses do Olimpo estão vivos, como Belzebu, Xangô, Iemanjá (...). Sim, Madame, também os de Nínive, Babilônia, mesmo aqueles que ignoramos, diluídos na solidão do Tempo. (...)

Não madame, não me refiro às sobrevivências nas supertições e costumes dos nossos dias, mas a eles mesmos personalidades miríficas que estão representadas, morfologicamente, em restos de mármores, camafeus, moedas, ex-votos." ${ }^{33}$

[ii] a intuição como processo aquisitivo de conhecimento,

"Tenho a intuição e madame sabe que a intuição é um processo aquisitivo do conhecimento, da vida eterna dos deuses, brancos, pretos, encarnados, verdes. Não, não vi ainda nenhum deles. A existência independe de comprovação." ${ }^{34}$

[iii] a imortalidade da alma, pois, se há uma alma para cada corpo, esta, no nível eterno, manterá a figura material que a alojou na terra,

"As almas não sucubem. São eternas desde a criação. (...) Quem tem alma viverá. Não estou enganado, Pilatos, sim." ${ }^{35}$

[iv] a duração da cultura brasileira pela via do colonizador português,

"Nós do Brasil, Madame, possuímos o panteão português. ... Os deuses encobertos seriam os deuses da divulgação romana." ${ }^{36}$

\footnotetext{
${ }^{33}$ Cascudo 1974: 5 .

${ }^{34}$ Cascudo 1974: 13.

${ }^{35}$ Cascudo 1974: 7.

${ }^{36}$ Cascudo 1974: 9.
} 
[v] resistência ao padrão, a norma dominante, pois os deuses não podem se restrijir às irradiações mentais captadas misteriosamente, e diametralemente opostas ao nosso critério e norma de conduta.

[vi] o pensar está na alma, como o fundamento da lógica cascudiana, cada um de nós é soma de individualidades disputadora de poder executivo na intimidade da vontade, aparentemente una, indivisível. Sentimos as vozes diversas, nos timbres característicos: o legislativo discutindo, o judiciário aconselhando, o executivo agindo ...

Posto isto, chegamos ao final da conversa e o velho professor conclui com sua interlocutora:

"Disse Platão no Fédon: 'As almas dos mortos, vivem!'

As impressões vêm vindo, a idéia brusca, veemente e fortuita, de Montaigne, repetindo-se, atingindo o córtex cerebral, encontrando o vestígio das reações anteriores. Uma assustadora contemporaneidade de milênios ....

A morte existe, os mortos, não!

Madame, o jantar está servido! ...” 


\section{Bibliografia Final}

AA.VV. (1990), Archéologie de la vigne et du vin. Actes du colloque 28-29 mai 1988, Paris.

AA.VV. (1992), Archeologia del paesaggio. IV Ciclo di lezioni sulla ricerca applicata in archeologia, Certosa di Pontignano (Siena) 14 - 26 gennaio 1991, Firenze.

AA.VV. (1997), Uomo, acqua e paesaggio. Atti dell'incontro di studio sul tema irreggimentazione delle acque e trasformazione del paesaggio antico, S. Maria Capua Vetere 22 - 23 novembre 1996, Roma.

AA.VV. (1998), El vi a l'antiguitat. Economia, producció i comerç al Mediterrani occidental. II Colloqui internacional d'arqueologia romana. Actes. Badalona, 6 - 9 de maig de 1998, Badalona.

AA.VV. (1999), El vino en la antigüedad romana. Simposio arqueología del vino, Jérez 2, 3 y 4 de octubre 1996, Madrid.

AA.VV. (1999b), Environmental reconstruction in Mediterranean landscape archaeology, Oxford.

AA.VV. (2001), La cerveza en la antigüedad, Sevilla.

AA.VV. (2004), Le vin. Nectar des dieux, génie des hommes, Gollion.

Abascal, J. Manuel, Espinosa, Urbano (1989), La ciudad hispano-romana. Privilegio y poder, Logronho.

Abásolo, J. A., Mayer, M. (1997), "Inscripciones latinas”, in S. Corchón (coord.), La Cueva de la Griega de Pedraza (Segovia), Zamora, 183-259.

Abbondanza, L. (ed.) (2008), Filostrato Maggiore, Milano.

Acosta-Hughes, B. (2002), Polyeideia. The Iambi of Callimachus and the Archaic Iambic Tradition, Berkeley and Los Angeles.

Adams, C. (2001), "There and back again. Getting around in Roman Egypt", in Adams, C. and R. Laurence (eds.), Travel and Geography in the Roman Empire, Londres and Nova Iorque, 138-166.

Adams, J. N. (2003), Bilingualism and the Latin language, Cambridge.

Adams, J. N. (2003a), “Romanitas and the Latin language”, CQ 53: 184-205.

Affatato, R. (2010), "Nueva York: recepción del mito de la ciudad en Federico García Lorca e Italo Calvino", in J. M. Losada Goya (ed.), Mito y mundo contemporáneo. La recepción de los mitos antiguos, medievales y modernos en la literatura contemporánea, Bari, 627-640.

Albuquerque, M. de (1968), O poder politico no Renascimento português, Lisboa.

Albuquerque, M. de (1981), "Bártolo e bartolismo na história do direito português”, Boletim do Ministério da Justiça 304: 41-61.

Albuquerque, M. de (1983), Estudos de cultura portuguesa, I, Lisboa. 
Alexandrescu-Vianu, M. (1988), “O nouă posibilă genealogie a familiei lui Hippolochos, fiul lui Theodotod, de la Histria”, SCIVA 39.3: 275-280.

Alexandrescu-Vianu, M. (1989), "Apollon Ietros. Ein verschollener Gott Ioniens?”, IstMitt 39: 115-122.

Alexandrescu-Vianu, M. (1990), "Die Steinskulptur von Histria", in P. Alexandrescu, W. Schuller (eds.) Histria. Eine Griechenstadt an der rumänischen Schwarzmeerkünste, Xenia. Konstanzer Althistorische Vorträge und Forschungen 25, Konstanz, 179-232.

Alexandrescu-Vianu, M. (2000), "Une alternative d'identification de la statue colossale d'Istros", in A. Avram, M. Babeş (eds.) Civilsation grecque et cultures antiques périphériques. Hommages à $P$. Alexandrescu à son $70^{\circ}$ anniversaire, Bucarest, 274-281.

Alexandridis, A. (2004), Die Frauen des römischen Kaiserhauses. Eine Untersuchung ibrer bildlichen Darstellung von Livia bis Iulia Domna, Mainz.

Alfayé, S., Marco, F. (2008), "Religion, language and identity in Hispania: Celtiberian and Lusitanian rock inscriptions", in R. Häußler (ed.), Romanisation et épigraphie. Etudes interdisciplinaires sur lacculturation et lidentité dans l,Empire romain, Montagne.

Alföldi, A. (1948), The conversion of Constantine and Pagan Rome, Oxford.

Alföldy, G. (1969), Fasti Hispanienses, Wiesbaden.

Alföldy, G. (1973), Flamines provinciae Hispaniae citerioris, Madrid.

Alföldy, G. (1991), "Augustus und die Inschriften: Tradition und Innovation. Die Geburt der imperialen Epigraphik”, Gymnasium 98: 289-324.

Allen, A. (1951), History of political thought in the sixteenth century. London

Altaner, B., Stuiber, A. (2a ed. 1972), Patrologia, São Paulo.

Amouretti, M.C., Brun J.-P. (eds.) (1993), La production du vin et de l'buile en Méditerranée. Actes du symposium international organisé par le Centre Camille Jullian et le Centre archéologique du Var, Aix-en-Provence et Toulon 20-22 novembre 1991 (BCH suppl. 26), Athènes.

Ando, C. (2003), "A Religion for the Empire", in A. J. Boyle, W. J. Dominik (eds.), Flavian Rome. Culture, Image, Text, Leiden, Boston 323-344.

Ando, C. (2006), "Interpretatio Romana”, in L. de Blois, P. Funke, J. Hahn, (eds.), The Impact of Imperial Rome on Religions, Ritual and Religious Life in the Roman Empire, Proceedings of the Fifth Workshop of the International Network Impact of Empire (Roman Empire 200 B.C. - A.D. 476.), Leiden, Boston 51-65.

Andrade, A. A. (1959), S. Tomás de Aquino no periodo áureo da filosofia portuguesa, Lisboa.

Andrade, A. A. de (1965), Antologia do pensamento politico português (séc. XVI), vol. I. Lisboa. 
Andrade, M. (1974), "Lira Paulistana”, in Poesias completas, São Paulo.

Andreu, J. (2004), Edictum, Municipium y Lex: Hispania en época flavia (69-96 d. C.), BAR Int. Ser. 1293, Oxford.

Antonietti, C. (1999), "Megara e le sue colonie: unità storico-culturale?”, in C. Antonetti, P. Lévêque (eds.) Il dinamismo della colonizzazione greca, Atti della tavola rotonda "Espansione e colonizzazione greca di età arcaica: metodologie e problemi a confront", Venezia, 10-11/11, Besançon-Paris, 17-24.

Aquino, T. de (1946), Des lois de Saint Thomas d'Aquin. Texte traduit et présenté par J. de la Croix Kaelin O. P., Paris.

Arnaldi, A. (2010), “Osservazioni sul flaminato dei Divi nelle provincie africane”, in M. Milanese, P. Ruggeri, C. Vismara, (eds.), L'Africa romana. Luoghi e le forme dei mestieri e della produzione nelle provincie africane. Atti del XVIII convegno di studio. Olbia 11-14 dicembre 2008, vol. III, Roma, 1645-1665.

Arruda, A. M. (2005), "O 10 milénio a.n.e. no Centro e no Sul de Portugal: leituras possíveis no início de um novo século", O Arqueólogo Português Série IV: 23: 59-74.

Arzone, A. (2011), “Alcune considerazioni sulle immagini di pietre miliari e sui riferimenti alle strade nel documento monetale", in I miliari lungo le strade dell'Impero. Caselle di Somma campagna Verona, 77-92.

Asensi, R. M., Musso, O. (1990), "Un documento etrusco di Tarragona", Quaderni della sezione di Studi Storici Alberto Boscolo 1: 5-11.

Aston, M. (1997), Interpreting the landscape. Landscape archaeology and local bistory, London.

$A T L=$ B.D. Meritt, WadeGery, H.T., McGregor, M.F., The Athenian Tribute Lists, 4 vs, Princeton.

Aubert, J.-M. (1955), Le droit romain dans l'oeuvre de Saint Thomas, Paris.

Avery, H. C. (1971), "Euripides' Heraclidae", AJPh 92: 539-565.

Avram, A., Lefèvre, F. (1995), "Les cultes de Callatis et l'oracle de Delphes", REG 108: 7-23.

Bacchielli, L. (1986), "Monumenti funerari a forma di cupula: origine e diffusione in Italia meridionale", in A. Mastino (ed.), L' Africa Romana: atti del 3. convegno di studio Sassari 13-15 dicembre 1985, Sassari, 303-319.

Bailly, A. (1963), Dictionnaire grec-français, Paris.

Balass, G. (s.d.), "The Female Breast as a Source of Charity: Artistic Depictions of Caritas Romana", www.Academia.edu/4006836.

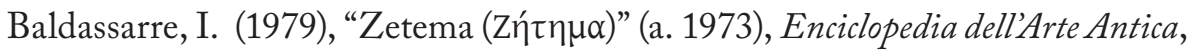
Suppl. 1979: 944-945.

Baldassarre, I., Bragantini, I., Morselli, C. and Taglietti, F. (1996), Necropoli di Porto. Isola Sacra, Roma. 
Balil, A. (1984-88), "Las cupae de Barcino. Contribución al estudio de un tipo de monumento funerario romano", Arqueologia e Historia: 111-115.

Baratta, G. (1993), “Una divinità gallo-romana. Sucellus. Un’ipotesi interpretativa”, ArchCl 45: 233-247.

Baratta, G. (1994), "Circa Alpes ligneis vasis condunt circulisque cingunt", ArchClass 46: 232-260.

Baratta, G. (1997), "Le botti: dati e questioni”, in Techniques et économie antique et médiévale. Le temps de l'innovation. Colloque international, Aix-enProvence 21-23 Mai 1997, Paris, 109-112.

Baratta, G. (1997), "Sucellus", in Enciclopedia dell'Arte Antica classica e orientale, Supplemento 1991-1994, V, Roma, 482.

Baratta, G. (2005a), "La cupa nell'ambito femminile: dalla caupona al loculus?”, in, F. Cenerini, A. Buonopane (eds.), Donna e vita cittadina nella documentazione epigrafica, 95-108.

Baratta, G. (2005b), Römische Kelteranlagen auf der italienischen Halbinsel. Ein Überblick über die schriftlichen, bildlichen und archäologischen Quellen (200 v.Chr. - 400. n.Chr.) (Cornucopia, 11), Murcia.

Baratta, G. (2005c), “Appunti sulle variabili e costanti dell' interpretatio religiosa nell'occidente romano, in F. de Oliveira, (ed.), Génese e consolidação da Ideia de Europa, vol.III, O Mundo Romano, Coimbra, 123-134

Baratta, G. (2006a), "Alcune osservazioni sulla genesi e la diffusione delle cupae", in Atti del XVI Convegno internazionale de L'Africa Romana (Rabat, 15-19 dicembre 2004), Roma, 355-368.

Baratta, G. (2006b), "Nuovi dati sull'iconografia delle mandorle nei sarcofagi strigilati. Un primo approccio ad un corpus", Annali della Facoltà di Lettere e Filosofia dell'Università di Macerata 26: 65-120.

Baratta, G. (2007), "La mandorla centrale dei sarcofagi strigilati. Un campo iconografico ed i suoi simboli", in F. Hoelscher, T. Hoelscher (eds.), Römische Bilderwelten. Von der Wirklichkeit zum Bild und zurück. Kolloquium der Gerda Henkel Stiftung am Deutschen Archäologischen Institut Rom, Heidelberg, 191-215.

Baron, H. (1938), "Cicero and the Roman civic spirit in the Middle Ages and the Early Renaissance", Bulletin of the John Rylands Library 22: 84-89.

Baron, H. (1970), La crisi del primo Rinascimento italiano, Firenze.

Barresi, P. (2007), "Il sofista Flavio Damiano di Efeso e la costruzione di termeginnasi nell'Asia Minore romana di età imperiale", in O. D. Cordovana, M. Galli, (eds.), Arte e memoria culturale nell'età della Seconda Sofistica, Catania, 137-151.

Barros, J. de (1919), Geografia d'Entre Douro e Minho e Trás-os-Montes, Porto. 
Barros, J. de (1937), Panegíricos - Panegírico de D. João III e da Infanta D. Maria, Texto restituído, prefácio e notas por M. Rodrigues Lapa, Lisboa.

Bassignano, M.S. (1974), I faminato nelle provincie romane dell'Africa, Roma.

Bastos, E. (1991), Entre o escândalo e o sucesso. A semana de 22 e o Armory show, Campinas.

Battaglia, M. (2003), "Il Vulcano dei Germani in Giulio Cesare (B.G. VI, 21, 1). Un caso di interpretatio?", Athenaeum 91: 373-401.

Beagon, M. (2005), The Elder Pliny on the Human Animal: Natural History Book 7, Oxford.

Beard, M., North, J., Price, S. (1998), Religions of Rome, vol. I, A History, Cambridge.

Behr, C.A. (ed.) (1973), Aristides, vol. I, Panathenaic Oration in Defence of Oratory, London.

Behrends, M. et alii (eds.) (2000), Hygin. L'oeuvre gromatique, Luxemburg.

Bejarano Osorio, A. M. (1996), "Sepulturas de incineración en la necrópolis oriental de Mérida: las variantes de cupae monolíticas", Anas 9: 37-58.

Belmonte, J. A. (2010), "Documentación fenicio-púnica en la Península Ibérica: estado de la cuestión", in G. Carrasco y J. C. Oliva (eds.), El Mediterráneo antiguo: lenguas y escrituras, Cuenca, 159-220.

Beltrán, F. ed. (1995), Roma y el nacimiento de la cultura epigráfica en occidente, Zaragoza.

Beltrán, F. (2000), "La vida en la frontera", in F. Beltrán, M. Martín-Bueno y F. Pina, Roma en la Cuenca Media del Ebro. La romanización en Aragón, Zaragoza.

Beltrán, F. (2002), "Identidad cívica y adhesión al príncipe en las emisiones municipales hispanas", in F. Marco, F. Pina y J. Remesal (eds.), Religión y propaganda politica en el mundo romano, Barcelona, 159-187.

Beltrán, F. (2004), "E1 latín en la Hispania romana: una perspectiva histórica", in R. Cano (ed.), Historia de la lengua española, Barcelona, 83-106.

Beltrán, F. (2004a), "Nos Celtis genitos et ex Hiberis. Apuntes sobre las identidades colectivas en Celtiberia", in G. Cruz Andreotti y B. Mora Serrano (eds.), Identidades étnicas - Identidades políticas en el mundo prerromano hispano, Kronion 1, Málaga, 87-145.

Beltrán, F. (2004b), “De nuevo sobre la tésera Froehner", Palaeohispanica 4: 4565.

Beltrán, F. (2004c), "Imagen y escritura en la moneda hispánica", in F. Chaves y F. J. García (eds.), Moneta qua scripta. La moneda como soporte de la escritura. Actas del III Encuentro Peninsular de Numismática Antigua, Anejos de AEspA 33: 125-139. 
Beltrán, F. (2004d), "Libertos y cultura epigráfica en la Hispania republicana", in F. Marco, F. Pina y J. Remesal (eds.), Vivir en tierra extraña: emigración e integración cultural en el mundo antiguo, Barcelona, 151-175.

Beltrán, F. (2005), "Cultura escrita, epigrafía y ciudad en el ámbito paleohispánico", Palaeohispanica 5: 21-56.

Beltrán, F. (2006), "Hispania y el Mediterráneo en los siglos II y I a. E.: diversidad cultural y movilidad social", in F. de Oliveira, P. Thiercy, R. Vilaça (eds.), O mar greco-latino, Coimbra, 223-240.

Beltrán, F. (2009), "Vltra eos palos. Una nueva lectura de la línea 7 de la Tabula Contrebiensis", in Espacios, usos y formas de la epigrafía hispana en épocas antigua y tardoantigua. Homenaje al Dr. Armin U. Stylow, Anejos de AEspA 48: 33-42.

Beltrán, F. (2011), "Lengua e identidad en la Hispania romana”, Palaeohispanica 11:19-59.

Beltrán, F. (2011a), “Firmas de artesano o sedes de asociaciones comerciales? A propósito de los epígrafes musivos de Caminreal (E.7.1), Andelo (K.28.1) y E1 Burgo de Ebro (HEp 11, 2001, 621 = AE 2001, 1237)", in E. Luján y J. M. García Alonso (eds.), A Greek man in the Iberian street. Papers in Linguistics and Epigraphy in honour of Javier de Hoz. Innsbrucker Beiträge zur Sprachwissenschaft 140, Innsbruck, 139-147.

Beltrán, F. (2011b), “Les colonies latines d'Hispanie (IIe siècle av. E.): émigration italique et intégration politique", in N. Barrandon y F. Kirbihler (eds.), Les gouverneurs et les provinciaux sous la République romaine, Rennes, 131-144.

Beltrán, F. (2012), "Roma y la epigrafía ibérica sobre piedra del nordeste peninsular", Palaeohispanica 12: 9-30.

Beltrán, F. (inédito), "Diversidad cultural y epigrafía: el ejemplo de Hispania", XII Congressus Internationalis epigraphiae Graecae et Latinae, Barcelona septiembre de 2002.

Beltrán, F., Estarán, M. J. (2011), “Comunicación epigráfica e inscripciones bilingües en la Península Ibérica”, in C. Ruiz Darasse y E. Luján (eds.), Contacts lingüistiques dans l'Occident méditerranéen antique. Collection de la Casa de Velázquez (126), Madrid, 9-25.

Beltrán, F., Velaza, J. (2009), "De etnias y monedas: las "cecas vasconas", una revisión crítica", in J. Andreu (ed.), Los vascones de las fuentes antiguas: en torno a una etnia de la antigüedad peninsular, Barcelona, 99-126.

Beltrán, F., Arasa, F. (1979-1980), "Los itineraria privata en la epigrafía latina”, Historia Antiqua, 9-10: 7-29.

Beltrán, F., Jordán, C., Marco, F. (2005), "Novedades epigráficas en Peñalba de Villastar (Teruel)", Palaeohispanica 5: 911-956.

Bentley, J. H. (1978), Politics and culture in Renaissance Naples, Princeton. 
Berciu, I.,Wolski, W. (1970), "Un nouveau type de tombe mise au jour à Apulum et le problème des sarcophages à voûte de l'Empire romain”, Latomus 29: 919-965.

Bergmann, M. (1998), Die Strablen der Herrscher. Theomorphes und politische Symbolik im Hellenismus und in der römischen Kaiserzeit, Mainz.

Berruti, V., Magistà, A. (eds.) (2009), L'automobile. Marche e modelli dalle origini a oggi, vol. 6, Lancia, Roma.

Besnier M., Chapot, V. (1913), "Via”, Dictionnaire des Antiquités Grecques et Romaines, 5, Paris, 777-817.

Bettini, C. (2008), “Tre Valascos nell'Italia del quatrocento: Meser Valasco di Vespasiano da Bisticci, Petrus Vallascis di Cataldo Siculo e Vasco Fernandes de Lucena", Humanitas 60: 205-226.

Bettini, M., Boldrini, M., Calabrese, O., Piccinni, G. (eds.) (2010), Miti di città, Siena.

Binsfeld, W. (1979), "Zu treverischen Kultdenkmälern”, in Festschrift 100 Jahre Rheinisches Landesmuseum Trier. Beiträge zur Archäologie und Kunst des Trierer Landes, Mainz, 263-269.

Blackman, D. (1969), "The Athenian Navy and Allied Naval Contributions in the Pentecontaetia", GRBS 10: 179-216.

Blanco Freijeiro, A. (1977), El puente de Alcántara en su contexto historico, Madrid.

Boardman, J. (1986), I Greci sui Mari. Traffici e Colonie, Trad. ital., Firenze, Giunti.

Boffo, L. (1975), "Cimone e gli alleatidi Atene”, RIL 109: 442-50.

Bol, R. (1984). Das Statuen programm des Herodes-Atticus-Nymphäums, Berlin.

Bona, G. (ed.) (1988), Pindaro. I peani, Cuneo.

Bonfante, G., Bonfante, L. (2002), The Etruscan language. An introduction. Revised edition, Manchester and New York.

Bonneville, J.-N. (1981), "Les cupae de Barcelone: les origines du type monumental", $M C V 17$ : 5-38.

Bontems, C. (1965), Le prince dans la France des XVIe e XVIIe siècles, Paris.

Bordenache, G. (1960), "Antichità greche e romane nel nuovo Museo di Mangalia”, Dacia N. S. 4: 489-509.

Bordenache, G. (1961), "Histria alla luce del suo materiale scultureo”, Dacia N. S., 185-211.fig. 16.

Bordenache, G. (1969), Sculture greche e romane del Museo Nazionale di Antichità di Bucarest I. Statue e rilievi di culto, elementi architectonici e decorativi, Bukarest.

Boschung, D. (1993a), Die Bildnisse des Augustus, Berlin. 
Boschung, D. (1993b), “Die Bildungstypen der julisch-claudischen Kaiserfamilie: ein kritischer Forschungsbericht", JRA 6: 39-79

Boschung, D. (2002), Gens Augusta. Untersuchungen zu Aufstellung, Wirkung und Bedeutung der Statuengruppen des julisch-claudischen Kaiserbauses, Mainz.

Boucher, S. (1987), "Limage et les fonctions du dieu Sucellus", Caesarodunum 23: 77-85.

Boulanger, A. (1923), Aelius Aristide et la sophistique dans la province d'Asie au II siècle de notre ère, Paris.

Bowersock, G.W. (1969), Greek Sophists in the Roman Empire, Oxford.

Braancamp Freire A. (ed.) (1916), Notícias da Vida de André de Resende pelo Beneficiado Francisco Leitão Ferreira, Lisboa.

Bracco, V. (1985), "Il tabellarius di Polla", Epigraphica 47: 93-97.

Brandão, M. (1937), Documentos de D. João III, I, Coimbra.

Brandt, H. (1998), Geschichte der römischer Kaiserzeit. Von Diokletian und Konstantin bis zum Ende der konstantinische Dynastie (264-363), Berlin.

Briant, P. (2002), From Cyrus to Alexander. A History of the Persian Empire, Winona Lake.

Brown, B.R. (1957), Ptolemaic Paintings and Mosaics and the Alexandrian style, Cambridge.

Brown, T. S. (1946), "Euhemerus and the Historians", HThR 39: 259-274.

Brun, J.-P. (1986), L'oléiculture antique en Provence. Les huiliers du departement du Var (RANArb suppl. 15), Paris.

Brun, J.-P. (2003), Le vin et l'huile dans la Méditerranée antique. Viticulture, oléiculture et procédés de transformation, Paris.

Brun, J.-P. (2004), Archéologie du vin et de l'huile dans l'empire romain, Paris.

Brun, J.-P. (2005), Archéologie du vin et d'buile en Gaule romaine, Paris.

Bruneau, P. (1985), "Deliaca. Iconographie. L'image de Delos personifiée e pyxides de Spina”, BCH 109: 551-556.

Búa, C. (1997), "Dialectos indoeuropeos na franxa ocidental hispânica”, in G. Pereira (ed.), Galicia fai dous mil anos. O feito diferencial galego, volumen I. Historia, Santiago de Compostela, 51-99.

Buck, R. J. (1979), A History of Boeotia, Edmonton.

Bulloch, A. W (1985), Callimachus. The Fifth Hymn, Cambridge.

Bulloch, A. W (2010), "Hymns and Encomia", in J. J Clauss and M. Cuypers (eds.), A Companion to Hellenistic Literature, Malden/Oxford, 166-180.

Burazacchini, G. (ed.) (2005), Troia tra realtà e legenda, Parma.

Burckhardt J. (1949), The Age of Constantine the Great, Berkeley. 
Burke, P. (1987 3a ed.), The italian Renaissance culture and society in Italy, Cambridge.

Burkert, W. (1991), Mito e Mitologia, Ed. 70, Lisboa.

Burkhalter-Arce, F. (2002), "Le tarif de Coptos". La douane de Coptos, les fermiers de l'apostolion et le préfet du desert de Bérénice”, Topoi Supp. 3: 199-233.

Burnett, A. P. (2005), Pindar's Songs for Young Athletes of Aigina, Oxford.

Bury, J. B., Cook, S. A., Adcock ,F. E. (eds.), The Cambridge Ancient History, Vol. 4, Cambridge.

Butcher, K. (2003), Roman Syria and the Near East, London.

Buxton, R. (ed.) (1999), From Myth to Reason? Studies in the Development of Greek Thought, Oxford.

Caccamo Caltabiano, M. (2003), "Messana/Tyche sulle monete della città dello stretto", in Archeologia del Mediterraneo. Studi in onore di Ernesto De Miro, Roma, 139-149.

Cadotte, A. (2007), La romanisation des dieux. L'interpretatio romana en Afrique du Nord sous le Haut-Empire (Religions in the Graeco-Roman world 158), Leiden.

Caiado, H. (1745), Eclogae et Sylvae et Epigrammata, in Pe. A. dos Reis, Corpus illustrium poetarum Lusitanorum, qui latine scripserunt, Lisboa.

Cairns, D. L. (2010), Bacchylides: five epinician odes (3, 5, 9, 11, 13), Cambridge.

Camia, F. (2011), Theoi sebastoi. Il culto degli imperatori romani in Grecia (provincia Achaia) nel secondo secolo D.C., Athinai.

Caldera de Castro, M. D. P. (1978), "Una sepultura de cupa hallada en Mérida. (Consideraciones acerca de estos monumentos funerarios)", Habis 9: 455-463.

Calderón Dorda, E., De Lazzer, A., Pellizer, E., (eds.) (2003), Corpus Plutarchi Moralium, Naples.

Calvino, I. (1996), "Diario americano, 1959-1966”, in Eremita a Parigi. Pagine autobiografiche, Milano, 20-124.

Calvino, I. (1996a), Città invisibili, Milano.

Camargos, M. (2001), Villa Kyrial: crônica da Belle Époque paulistana, São Paulo.

Cameron A. (1993), The later Roman empire: AD 284-430, Cambridge.

Cantemir, D. (2006), The Salvation of the Wise Man and the Ruin of the Sinful World [...], ed., trans., notes, indices Ioana Feodorov, Editura Academiei, Bucuresti.

Cantemirius, D. (1973), Descriptio antiqui et hodierni status Moldaviae/ Dimitrie Cantemir, Descrierea Moldovei, trans. Gh. Gutu, introd. Maria Holban, hist. com. N. Stoicescu, cartographical study Vintilă Mihailescu, index Ioana Constantinescu, note D. M. Pippidi, Bucuresti. 
Bibliografia

Cantemirius, D. (2006), Descriptio antiqui et hodierni status Moldaviae/ Dimitrie Cantemir, Principele Moldovei, Descrierea stării de odinioară şi de astăzi a Moldovei, ed., trans. Dan Slusanschi, Bucuresti.

Cantineau, J. (1935), Grammaire du palmyrénien épigraphique, Le Caire.

Carcopino, J.(s/d), A vida quotidiana em Roma no apogeu do Império (trad A. J. Saraiva), Lisboa.

Cardim Ribeiro, J. (2002), "Soli Aeterno Lunae. O santuário", Religiões da Lusitânia. Loquuntur Saxa, Lisboa, 235-239.

Cardim Ribeiro, J. (2005), "O deus sanctus Endovellicus durante a romanidade. Uma interpretatio local de Faunus-Silvanus?”, Paleohispanica 5: 721-766.

Carlier p. (1990), Démosthène, Paris.

Carneiro, A., d'Encarnação, J., de Oliveira, J., Teixeira, Cl. (2008), "Uma iscrição votiva em lengua lusitana”, Palaeobispanica 8: 167-178.

Caro, A. (2009), “Una fase decisiva en la evolución de la publicidad: la transición del producto a la marca", Pensar la publicidad, III, 2: 109-114.

Caro, A. (2010), Comprender la publicidad, Barcelona.

Cartledge, P. (2009), Ancient Greek Political Thought in Practice, Cambridge.

Carvalho, J. de (1947-1948), Estudos sobre a cultura portuguesa do século XVI, 2 vols. Coimbra.

Carvalho, J. de (1949), Estudos sobre a cultura portuguesa do século XV, Coimbra.

Cascudo, L. C. (1974), Prelúdio e fuga do real, Natal.

Cascudo, L. C. (1983), Civilização e Cultura, pesquisas e notas de etnografia geral, Belo Horizonte.

Cascudo, L. C. (1983, 2ª ed.), Anúbis e outros ensaios. Mitologia e folclore, Rio de Janeiro, Natal.

Cascudo, L. C. (1987), História dos nossos gestos, Belo Horizonte, São Paulo.

Cascudo, L.C. (1966), "História de um livro perdido", Arquivos do Instituto de Antropologia "Câmara Cascudo" 2.1-2: 5-19.

Castelli, E. (1951) (ed.), Umanesimo e Scienza politica. Atti del congresso Internazionale di Studi Umanistici, Roma-Firenze, 1949, Milano.

Castillo, C. (1998), "Los flamines provinciales de la Bética", REA 100: 437-460

Cawkwell, G. (2005), The Greek Wars. The Failure of Persia, Oxford.

Cesarano, M. (2015), In honorem domus divinae. Introduzione allo studio dei cicli statuari giulio-claudii a Roma e in Occidente, Roma.

Clauss, M. (1979), Kaiser und Gott: Herrscherkult im romischen Reich, Berlin.

Chamie, M. (2009), Paulicéia dilacerada, Ribeirão Preto.

Chaniotis, A. (2009), "The Dynamics of Rituals in the Roman Empire", in O. 
Hekster, S. Schmidt-Hofner, Chr. Witschel (eds.), Ritual Dynamics and Religious Change in the Roman Empire. Proceedings of the Eight Workshop of International Network Impact of Empire, Leiden, Boston, 3-29

Charles-Picard, G., Rougé, J. (1969), Textes et documents relatifs à la vie economique et sociale dans l'Empire romain, Paris.

Chassaing, M. (1961), "Les barillets frontiniens“, RAE 12: 7-33, 89-106.

Chelotti, M. (2003), Regio II, Apulia et Calabria, Venusia (Supplementa Italica 20), Roma.

Cherry, D. (1998), Frontier and Society in Roman North Africa, Oxford.

Chevallier, R. (1972), Les voies romaines, Paris.

Chevallier, R. (1988), Voyages et déplacements dans l'Empire romain, Paris.

Chiarelli, G. (1932), 'Il 'De regno' di Francesco Patrizi', Rivista internazionale di filsosofia del diritto, Anno XII. (Nov-Dec.): 716-738.

Cistercienses (Os). Documentos primitivos. Texto latino e tradução brasileira. (1997) Introdução e bibliografia Irmão François de Place, Tradução de Irineu Guimarães, Musa, S. Paulo; Lúmen Christi, Rio de Janeiro 1997.

Clauss, J., Cuypers, M. (eds.) (2010), A Companion to Hellenistic Literature, Chichester, West Sussex.

Clavel-Lévêque, M. et alii (eds.) (1993), Siculus Flaccus. Les conditions des terres, Nápoles.

Clavel-Lévêque, M. et alii (eds.) (1996), Hygin l'arpenteur. L' établissement des limites, Nápoles.

Clayton, P.A. (1989), Le sette Meraviglie del mondo, Torino. (The Seven Wonders of the Ancient World, London, 1988).

Cogitore, I. (1996), “Séries de dédicaces italiennes à la dynastie julio-claudienne”, MEFRA 104 : 817-870.

Colasso, F. (1951), "Umanesimo giuridico", in E. Castelli (ed.), Umanesimo e Scienza politica (Atti dei Congresso Internazionale di Studi Umanistici, Roma-Firenze, 1949), Milano, 57-58.

Colecchia, A., Bertolani, G. B., Marcante, A. et alii (2004), L'Alto Garda occidentale dalla preistoria al postmedioevo. Archeologia, storia del popolamento e trasformazione del paesaggio (Documenti di archeologia, 36), Mantova.

Colonna, G. (1980), "Virgilio, Cortona e la leggenda etrusca di Dardano", Archeologia Classica 32: 1-15.

Conger, G. P. (1952), "Did India influence Early Greek Philosophies?", Philosophy East and West 2.2: 102-128.

Conti, S. (1997), "Dinastia giulio-claudia a Roselle: una serie di dediche imperiali in Etruria”, Ann. Fac. Lett. e Filos. Univ. Siena 18: 101-127. 
Conti, S. (1998), Rusellae, Suppl. It. n. s. 16, Roma.

Cook, J. M. (1971), Os Gregos na Iónia e no Oriente, Lisboa.

Cooley, A. E. (ed.) (2002), Becoming Roman, Writing Latin? Literacy and Epigraphy in the Roman West. JRA Suppl. Ser. 48, Portsmouth.

Cooley, A. E. (2002), "The survival of Oscan in Roman Pompeii”, in E. A. Cooley (ed.), Becoming Roman, Writing Latin? : Literacy and Epigraphy in the Roman West, JRA Suppl. Ser. 48: 77-86.

Cordovana, O. D., Galli, M. (eds.) (2007), Arte e memoria culturale nell'età della Seconda Sofistica, Catania.

Corell, J. (1989), “Notas sobre epigrafía romana del País Valenciano”, APL 19: 271-281.

Costa, A. D. S. (1969), Estudantes portugueses na reitoria do Colégio de S. Clemente de Bolonha na primeira metade do século XV, Lisboa.

Costa, A. D. S. (1990), Portugueses no Colégio de S. Clemente e Universidade de Bolonha durante o século $X V$, vol. I, Bolonia.

Coulanges, F. de. (1971, 10ª ed.), A cidade antiga, Trad. e glossário de Fernando de Aguiar, Livraria Clássica Editora, Lisboa.

Crawford, M. H., Reynolds, J. M. (1979), “The Aezani copy of the Prices Edict”, Zeitschrift für Papyrologie und Epigraphik 34: 163-210.

Crystal, D. (2000), Language death, Cambridge.

Curado, F. P. (1985), "Inscrição rupestre de Freixo de Numão”, Ficheiro Epigráfico 11: no48.

David, B., Thomas J. (eds.) (2008), Handbook of landscape archaeology (World archaeological congress research handbooks in archaeology, 1), Walnut Creek.

Davie, J. N. (1982), "Theseus the king in fifth-century Athens", GE'R 29.1: 2534.

DCPH = M. P. García-Bellido y C. Blázquez (2001), Diccionario de cecas y pueblos hispánicos, Madrid.

De Bernardo Stempel, P. (2008), "More names, fewer deities. Complex theonymic formulas and the three types of interpretation", in Divindades indígenas em análise. Divinités pré-romaines. Bilan et perspectives d'une recherche. Actas do VII workshop FERCAN, Cascais, 25-27.5.2006, Coimbra, 65-73.

De Hoz, J. (2001), "La lengua de los íberos y los documentos epigráficos en la comarca de Requena-Utiel”, in A. J. Lorrio (ed.), Los íberos en la comarca de Requena-Utiel (Valencia), Madrid, 49-62.

De Hoz, J. (2010), Historia lingüistica de la Península Ibérica en la Antigüedad. I. Preliminares y mundo meridional prerromano, Madrid. 
De Hoz, M. P. (1997), “Epigrafía griega en Hispania”, Epigraphica 59: 29-93.

De Labriolle, P. (1934), La reaction païenne, Paris.

De Martino, D. (2010), "Spot, etica e letteratura", La nuova ricerca. Pubblicazione annuale del Dipartimento di Linguistica, Letteratura e Filologia moderna dell'Università degli studi di Bari, anno XIX. 19, 117-128.

De Martino, D. (2010 bis), "Automobili da mito", in F. De Martino (ed.), Antichità Ẽ pubblicità, Bari, 443-522.

De Martino, D. (2011), Io sono Giulietta. Letterature E' miti nella pubblicità di auto, Bari.

De Martino, D. (2012), "Una forma de subversión del mito literario: de la novela a la publicidad", in J. M. Losada Goya, M. Guirao Ochoa (eds.), Myth and Subversion in the Contemporary Novel, Cambridge, 421-436.

De Martino, D. (2013), Dante E̋ la pubblicità, Bari.

De Martino, F., Vox, O. (1996) (eds.), Lirica greca, vol. 3, Bari.

De Ruyt, Cl. (1983), Macellum. Marché alimentaire des romains, Louvain-laNeuve.

De Santerre, H. H. (1976), "Athènes, Délos et Delphes d'après une peinture de vase à figure rouges du V siècle avant J.-C.”, BCH 100: 291-298.

De Vos, M., Andreoli, M., Attoui, R. et alii (2007), "Cilicia campestris orientale. Leconomia rurale e la trasformazione del paesaggio intorno al Karasis", in Geografia e viaggi nell'antichità. Atti del convegno internazionale di studi (Certosa di Pontognano, 9-10 ottobre 2005), Siena, 13-39.

Degl'Innocenti Pierini, R. (2012), "Le città personificate nella Roma repubblicana: fenomenologia di un motivo letterario tra retorica e poesia", in G. Moretti, A. Bonandini (eds.), Persona ficta. La personificazione allegorica nella cultura antica, fra letteratura, retorica e iconografia, Trento, 215-247.

Desbat, A. (1991), "Un bouchon de bois du Ier s. aprés J.-C. recueilli dans la Saône à Lyon et la question du tonneau à 1'époque romaine", Gallia 48: 319-336.

Dias, P. B. (2011 2a ed.), “Notas introdutórias”, in J. G Freire, A versãolatina por Pascásio de Dume dos Apophtegmata Patrum, Coimbra, 1-34.

Dias, P. B. (2012), “Cristianismo e responsabilidade cristã na queda de Roma”, in F. Oliveira et alli (coords.), A queda de Roma e o alvorecer da Europa, Coimbra, 43-67.

Dias P. B. (2013), "O legado de Constantino na identidade da Europa cristã: dois casos de estudo", in M. C. Pimentel e P. Farmhouse Alberto (orgs.), Vir bonus peritissimus aeque. Estudos de homenagem a Arnaldo do Espirito Santo, Lisboa, 455-463 
Díaz, B. (2008), Epigrafía latina republicana de Hispania, Barcelona.

Dittenberger, W., Purgold, K. (1896), Inschriften von Olympia, Berlin.

Dixon, R. M. W. (1997), The rise and fall of languages, Cambridge.

Domăneanțu, C. (1993), "Un sanctuaire hellénistique du site de Nuntaşi II (comm. d'Istria, dep. De Constanța)”, Dacia 37: 59-78.

Dörfler, W., Evans, A., Löhr, H. (1998), “Trier, Walramsneustrasse. Untersuchungen zum römerzeitlichen Landschaftswandel im Hunsrück-Eifel-Raum an einem Beispiel aus der Trierer Talweite“, in Studien zur Archäologie der Kelten, Römer und Germanen in Mittel- und Westeuropa. Alfred Haffner zum 60. Geburtstag gewidmet, Rahden, 119152.

Dubuisson, M. (1981), "Utraque lengua”, L'Antiquité Classique 50: 274-286.

Dubuisson, M. (1982), "Y a-t-il une politique linguistique romaine?”, Ktéma 7: 197-210.

Duchesne, L. (1887), "Le concile d'Elvire et les flamines chrétiens", Mélanges Renier, Paris, 159-174.

Dunkle, J. R. (1969), “The Aegeus episode and the theme of Euripides' Medea", TAPhA 100: 97-107.

Durán Fuentes, M. (2005), La construcción de puentes romanos en Hispania, Santiago de Compostela.

Eck, W. (2006), "Herrschaft und Kommunikation in antiken Gesellschaften. Das Beispiel Rom", in U. Peter, S. J. Seidlmayer (eds.), Mediengesellschaft Antike? Information und Kommunikation vom Alten Ägypten bis Byzanz, Berlin, 11-33.

Eco, U. (2013), Storia delle terre e dei luoghi leggendari, Milano.

Eddy, S.K. (1968), “Four Hundred Sixty Talents Once More”, CP 63: 184-95.

Edmonson, J. (1997), “Two dedications to Divus Augustus and Diva Augusta from Augusta Emerita and the early development of the imperial cult in Lusitania", MM 38: 89-105.

Edmondson, J. (2002), "Writing latin in the province of Lusitania", in A. E. Cooley (ed.), Becoming Roman, Writing Latin? Literary and Epigraphy in the Roman West, JRA Suppl. Ser. 48: 41-60.

Ehrenberg, V. (1973, 2a ed.), From Solon to Sócrates, Londres.

Ehrenberg, V. (1976), L'État grec, Paris.

Ehrhardt, N. (1988), Milet und seine Koloniei. Vergleichende Untersuchung der kultischen und politischen Einrichtungen, ed. a II-a, Frankfurt, Main-Bern, New York, Paris.

Elliger, W. (1975), Die Darstellung der Landschaft in der griechischen Dichtung, Berlin, New York. 
Elliott, Th. (1990), “The Language of Constantinian Propaganda”, TAPhA 120: 349-353.

Encarnação, J. d' (1984), Inscrições romanas do Conventus Pacensis, Coimbra.

Erasmo, D. (1703), Opera omnia (in decem tomos distincta), Recognovit Joannes Clericus, Leiden.

Erodoto (1988), Le Storie. Libro I. La Lidia ela Persia. Acura di David Astheri, Milano.

Erskine, A. (ed.) (2003), A Companion to the Hellenistic World, Oxford.

Espérandieu, E. (1907-1981), Recueil général des bas-reliefs, statues et bustes de la Gaule romaine, Paris.

Estarán, M. J. (2012), “Las estampillas ibérico-latinas K.5.4”, Palaeohispanica 12: $73-90$

ET = Rix, H. (1991), Etruskische Texte, Tübingen.

Étienne, R. (1958), Le culte impérial dans la Péninsule ibérique d’Auguste à Diocletien, Paris.

Étienne, R. (1973), "Les syncrétismes dans la Péninsule Ibérique à l'époque impériale", in Les syncrétismes dans les religions grecque et romaine, Paris, 153-163.

Étienne, R., Fabre, G.; Lévêque, P. et M. (1976), Fouilles de Conimbriga, vol. II, Épigraphie et Sculpture, Paris.

Étienne, R., Fabre, G., Le Roux, P., Tranoy, A. (1976), "Les dimensions sociales de la romanisation dans la Péninsule Ibérique des origines à la fin de l'Empire", in D. M. Pippidi (ed.), Assimilation et résistance à la culture gréco-romaine dans le monde ancien. Travaux du VI Congrès International d'Études Classiques, Bucureşti, Paris, 95-107.

Étienne, R., Mayet, F. (2000), Le vin hispanique, Paris.

Evans, J. A. S. (1981), "Notes on the debate of the Persian Grandees in Herodotus 3, 80-82”, QUCC 36: 79-84.

Evers, C. (1994), Les portraits d'Hadrien. Typologie et ateliers, Bruxelles.

Ewald, C., Norena, C. F. (eds.) (2010), The Emperor and Rome: Space, Representation, Ritual, Cambridge.

Fabre, G., Mayer, M., Rodà, I. (1991), Inscriptions romaines de Catalogne, III, Paris.

Fayer, C. (1976), Il culto della dea Roma. Origine e diffusione nell'Impero, Pescara.

Fearn, D. (2007), Bacchylides. Politics, performance, poetic tradition, Oxford.

Fernandes, L., Carvalho, P., Figueira, N. (2009), "Divindades indígenas numa ara inédita de Viseu", Palaeohispanica 9: 143-155.

Fernández Gallardo, L. (2002), Alonso de Cartagena. Una biografía politica en la Castilla del siglo XV, Valladolid. 
Fernández Gallardo, L. (2008), “Alonso de Cartagena y el Humanismo”, La Corónica 37.1: 175- 215.

Ferraz, C. (2002), "Conjunto de oito aras provenientes do Lararium de Centum Celas", in V. L. Raposo, J. R. Ferreira (Coords.), Religióes da Lusitânia. Loquuntur Saxa, Lisboa, 467-469.

Ferreira, J. R. (1988), "Grécia e Roma na Revolução Francesa”, Revista de História das Ideias 10: 203-234.

Ferreira, J. R. (1990), A democracia na Grécia Antiga, Coimbra.

Ferreira, J. R. (1990a), Participação e poder na democracia grega, Coimbra.

Ferreira, J. R. (1993), Hélade e Helenos I - Génese e Evolução de um Conceito, Coimbra.

Ferreira, J. R. (2004 2a ed.), A Grécia Antiga. Sociedade e Politica, Lisboa.

Ferreira, J. R., (1991), "Presença da Grécia e de Roma na Revolução Francesa", in Actas do colóquio A Recepção da Revolução Francesa em Portugal e no Brasil, Porto, vol. I, 75-96.

Ferri, S. (1976), "Luci e ombre sulla interpretatio romana", in Convegno internazionale "Renania romana" Roma 14-16 aprile 1975, Roma, 125133.

Ferrill, A. (1978), "Herodotus on tyranny", Historia 27.3: 385-398.

Figueira, T. J. (1998), The Power of Money: Coinage and Politics in the Athenian Empire, Philadelphia.

Figueira, T. J. (2003), "Economic Integration and Monetary Consolidation in the Athenian Arkhê", in G. Urso (ed.), Moneta, Mercanti, Banchieri. I precedenti greci e romani dell'Euro, Pisa, 71-92.

Figueira, T. J. (2005), "The Imperial Commercial Tax and the Finances of the Athenian Hegemony”, Incidenza dell'antico 3: 83-133.

Figueira, T. J. (2006), "Reconsidering the Athenian Coinage Decree", AIIN 52: 9-44.

Figueira, T. J. (2011), "The Athenian Naukraroi and Archaic Naval Warfare”, Cadmo. Revista de História Antiga 21: 183-210.

Figueira, T. J. (forthcoming[a]), "Archaic Naval Warfare”, in N. Birgalias (ed.), Great is the Power of the Sea: The Power of Sea and Sea Powers in the Greek world of the Archaic and Classical Periods, Athens.

Figueira, T. J. (forthcoming[b]), "The Aristeidian Tribute on the Peace of Nikias", in S. Jensen, T. Figueira (eds.), Athenian Hegemonic Finances, Swansea.

Figueira, T. J. (forthcoming[c]), "Community Wealth and Military Might in Periclean Athens", in A.L. Pierris (ed.), Mind, Might, Money: The Secular Triad in Classical Athens, Patras. 
Figueira, T. J. (forthcoming[d]), “Aigina: Island as Paradigm”, in A. Powell and K. Meidani (eds.), The Eyesore of Aigina: Anti-Athenian Attitudes in Greek, Hellenistic and Roman History, Swansea.

Figueiredo, R., Lamounier, B. (1996), As cidades que dão certo, Brasília.

Finley, M.I. (1966), The Ancient Greeks. An introduction to their life and thought, Londres. Trad. port.: Os Gregos Antigos (Lisboa, 2a ed. 1988).

Finley, M. I. (1973, 2a ed.), Democracy, ancient and modern, London.

Finley, M.I. (1973a), The ancient economy, London.

Finley, M.I. (1982), Authority and legitimacy in the classical city-state, Kobenhavn.

Fishwick, D. (1970), "Flamen Augustorum”, HSCPh 74: 299-312.

Fishwick, D. (1982), "The altar of Augustus and the municipal cult of Tarraco", MM 23: 222-233

Fishwick, D. (2002), The Imperial Cult in the Latin West, 3/2, Provincial Cult I The Provincial Priesthood, Leiden.

Fishwick, D. (2005), The Imperial Cult in the Latin West. Studies in the Ruler Cult of the Western Provinces of the Roman Empire, Leiden, Boston.

Fitton, J. W. (1961), "The Suppliant Women and the Herakleidai of Euripides", Hermes 89.4: 430-461.

Flower, M. F. (2007), "Appendix R: The Size of Xerxes Expeditionary Force," in Robert B. Strassler (ed.), The Landmark Herodotus: The Histories, New York, 819-23.

Fonseca, L. A. (1982), O Condestável D. Pedro de Portugal, Porto.

Fontanella, F. (2008), "The Encomium on Rome as a response to Polybius' doubts about the Roman Empire", Columbia Studies in the Classical Tradition 33: 203-216.

Forni, G. (1973), "El culto de Augusto en el compromiso oficial y en el sentimiento oriental", BSAA 39: 105-113.

Forni, G. (1994), Scritti vari di Storia, Epigraphia e antichità romane, Roma.

Franck, A. D. (1864), Réformateurs et publicistes de l'Europe: Moyen ÂgeRenaissance, Paris.

French, A. (1972), "The Tribute of the Allies", Historia 21: 3-20.

Fuentes, M. J. (1986), Corpus de las inscripciones fenicias, púnicas y neopúnicas de Hispania, Barcelona.

Gabba, S., Drioton, É. (1954), Peintures à fresques et scènes peintes a Ermoupolis Ouvest (Touna el-Gevel), Le Caire.

Gaffiot, F. (s/d), Dictionnaire latin-français, Paris.

Gagé, J. (1936), "Le templum Urbis et les origines de l'idée de Renovatio", in Mélanges Franz Cumont, Bruxelles, 151-187. 
Gagé, J. (1955), Apollon romain. Éssai sur le culte d'Apollon et le développement du "ritus Graecus" à Rome des originrs à Auguste, Paris.

Gagé, J. (1968), "Basiléia”. Les Césars, les rois d'Orient et les "mages", Paris.

Gagé, J. (1974), "Le solemne Urbis du 21 avril au III" siècle ap. J.-C.: Rites positives et speculations séculaires", Mélanges d'histoire de religions offerts à Henri-Charles Puech, Paris, 225-241.

García Bellido, M. P. (1993), "Sobre el culto de Volcanus y Sucellus en Hispania. Testimonios numismáticos", in F. Burkhater, J. Arce (eds.), Bronces y religión romana. Actas del XI Congreso internacional de bronces antiguos, Madrid mayo - junio 1990, Madrid, 161-170.

García Iglésias, L. (1976), "Autenticidad de la inscripción de municipios que sufragaron el puente de Alcántara”, Revista de Estudios Extremeños 32.2: 263-276.

García Jurado, F. (2007), Aulo Gelio, Noches Aticas. Antología, Madrid.

García Romero, F. (2002), "Pervivencia de Penélope”, in C. Morenilla Talens, F. De Martino (eds.), El perfil de les ombres, Bari, 187-204.

García Soler, M. J. (2010), "Gastronomia e pubblicità nella Grecia antica”, in F. De Martino (ed.), Antichità Ẻ pubblicità, Bari, 345-366.

Garin, E. (1955), "Ricerche sulle traduzioni di Platone nella prima metà del XV secolo", Medioevo e Rinascimento, Studi in onore di B. Nardi, Firenze.

Garin, E. (1966), Storia della filosofia italiana, Torino.

Garriguet, J. A. (2004), "Grupos estatuarios imperiales de la Bética: la evidencia escultórica y epigráfica”, in Actas de la IV reunión sobre escultura romana en Hispania, Madrid, 67-101.

Gasperini, L. (1977), “L’Augusteo di Firmo Piceno in un'epigrafe da rileggere”, AFML 10: 57-87.

Gasperini, L. (2008), "L’Augusteo di Forum Clodii”, en L. Gasperini, G. Paci, (eds.), Nuove ricerche sul culto imperiale in Italia, Tivoli, 91-134.

Gasperini, L., Paci, G. (eds.) (2008), Nuove ricerche sul culto imperiale in Italia, Tivoli.

Gaudemet J. (1947), “La législation religieuse de Constantin”, Rérue d' Histoire de l'Église de France 122: 25-61.

Genette, G. (1997), Palinsesti. La letteratura di secondo grado, Torino.

Gentili, B. (ed.) (1995), Pindaro. Le pitiche, Milano.

Ghedini, F. (2000), "Filostrato Maggiore come fonte per la conoscenza della pittura antica”, Ostraka 9.1: 75-197.

Giachero, M. (ed.) (1974), Edictum Diocletiani et Collegarum de pretiis rerum venalium in integrum restitutum e latinis gracisque fragmentis, 1-2, Génova. 
Gico, V. (1998), "Luís da Câmara Cascudo: perfil bibliográfico", in L. C. Cascudo, Ontem. (Maginaçôes e notas de um professor de provincia), Natal.

Gigli, D. (1985), Metafora e poetica in Nonno di Panopoli, Firenze.

Gilles, K. J. (1987), "Römische Glasgefäße", in AA.VV., 2000 Jahre Weinkultur an Mosel-Saar-Ruwer. Denkmäler und Zeugnisse zur Geschichte von Weinbau, Weinhandel, Weingenuß, Trier, 143-145.

Gilles, K. J. (1987b), “Trierer Weinkeramik”, in AA.VV., 2000 Jabre Weinkultur an Mosel-Saar-Ruwer. Denkmäler und Zeugnisse zur Geschichte von Weinbau, Weinhandel, Weingenuß, Trier, 132-133.

Gilles, K. J., König, M., Schumann, F. (1995), Neuere Forschungen zum römischen Weinbau an Mosel und Rhein (Schriftenreihe des Rheinischen Landesmuseums Trier, 11), Trier.

Gilson, É. (1983, 6ª ed.), Le thomisme, Paris.

Gómara, M. (2007), "Una inscripción paleohispánica sobre cerámica altoimperial en Cascante (Navarra)", Palaeohispanica 7: 263-268.

Gomes, S.A. (1998), Visitações a mosteiros cistercienses em Portugal. Séculos XVe XVI, Ministério da Cultura - IPPAR, Lisboa.

Gomes, S. A. (2000), "Revisitação a um velho tema: a fundação do Mosteiro de Alcobaça”, in Cister: Espaços Território e Paisagens. Colóquio Internacional, 16-20 Junho de 1998, Mosteiro de Alcobaça. Actas. I, Lisboa, 27-72.

Gomes, S. A. (2000), O mosteiro de Alcobaça na transição dos séculos XIV e XV: o protagonismo de D. João Dornelas, in Cister. Espaços, Territórios, Paisagens. Colóquio Internacional. 16-20 Junho 1998. Mosteiro de Alcobaça, Lisboa, 73-88.

Gomes, S. A. (2006), D. Afonso V, Círculo de Leitores-Colecção Reis de Portugal, Lisboa.

Gómez García, C. (2010), "La configuración de la ciudad de Berlin”, in J. M. Losada Goya (ed.), Mito y mundo contemporáneo. La recepción de los mitos antiguos, medievales y modernos en la literatura contemporánea, Bari , 617626.

González Rolán, T., P. Saquero Suárez-Somonte, P. (2001), “E1 Humanismo italiano en la Castilla del cuatrocientos: estudio y edición de la versión castellana y del original latino del De infelicitate principum de Poggio Bracciolini “, Cuadernos de Filología Clásica. Estudios Latinos 21: 115-150.

González Rolán, T., Moreno Hernández, A., Saquero Suárez-Somonte, P. (2000), Humanismo y teoría de la traducción en España e Italia en la primera mitad del siglo XV. Edición y estudio de la Controversia Alphonsiana (Alfonso de Cartagena vs. L. Bruni y P. Candido Decembrio), Madrid.

Gorrochategui, J. (1987), "Situación lingüística de Navarra y aledaños en la antigüedad a partir de las fuentes epigráficas", Primer Congreso General de Historia de Navarra II, Pamplona, 435-445. 
Gorrochategui, J. (2014), "Nueva inscripción funeraria celtibérica procedente de Clunia”, Palaeobispanica 14: 229-236.

Gorrochategui, J.y Vallejo, J. M. (2010), “Lengua y onomástica. Las inscripciones lusitanas", Iberografías 6: 71-80.

Gose, E. (1976), Gefäßtypen der römischen Keramik im Rheinland, Köln.

Graham, A.J. (1964), Colony and Mother City, Manchester.

Grenier, A. (1934), Manuel d'archéologie gallo-romaine 2, Les routes, Paris.

Gros, P., Marin, M., Zink, M. (eds.) (2015), Auguste, son époque et l'Augusteum de Narona. Actes du colloque organisé à l 'Académie des Inscriptions et Belles-letres le 12 décembre 2014, Paris.

Gualandi, M. L. (2001), Le fonti per la storia dell'arte - I. L'antichità classica, Roma.

Guarducci, M. (1974), Epigrafia greca, vol. III, Roma.

Guarducci, M. (1978), Epigrafia greca, vol. IV, Roma.

Guerra, A., Schatner, T. (2010), "El foro y el templo de Lancia Oppidana: nueva interpretación de Centum Celas (Belmonte)", in T. Mogale Basarrate (ed.) Ciudad y Foro en Lusitania Romana, Mérida, 333-342.

Guilaine, J. (cur.) (1991), Pour une archéologie agraire: à la croisée des sciencies de l'homme et de la nature, Paris.

Guilmartin, J. F. (2002), Galleons and Galleys, London.

Guilmartin, J. F. (2003), Gunpowder and Galleys. Changing Technology and Mediterranean Warfare at Sea in the Sixteenth Century, 2nd ed., Annapolis.

Hall, J. M. (1997), Ethnic identity in Greek Antiquity, Cambridge.

Hanell, K. (1934), Megarische Studien, Lund.

Hänlein-Schäfer, H. (1985), Veneratio Augusti. Eine Studie zu den Tempeln der ersten römischen Kaisers, München.

Hanley, R. (2000), Villages in Roman Britain, Princes Risborough.

Hansen, H. M. (1991), The Athenian Democracy in the age of Demosthenes. Structure, Principles and Ideology, Oxford.

Hardy, E. G. (1925), "The Lex Mamilia Roscia Peducaea Alliena Fabia”, The CQ 19 (3/4): 185-191.

Harris, E. (1995), Aeschines and Athenian Politics, Oxford.

Harth, H. (1984), Poggio Bracciolini, Lettere, Leo S. Olschki Editore, Florencia.

Hekster, O., Schmidt-Hofner, S., Witschel, Chr. (eds.) (2009), Ritual dynamics and Religious Change in the Roman Empire. Proceedings of the Eighth Workshop of the International Network Impact of Empire, Leiden, Boston.

Helck, W. (1971), Das Bier im alten Ägypten, Berlin. 
Hershowitz, A., (forthcoming), "Patterns in Variation in Tribute Assessment", in S. Jensen, T. Figueira (eds.), Athenian Hegemonic Finances, Classical Press of Wales, Swansea.

Herta, P. (1978), "Bibliographie zum römischer Kaiserkult (1955-1975)", ANRW II 18: 833-910.

Heubeck, A. (ed.) (1983), Omero. Odissea, Volume III (Libri IX-XII), Milano.

Heurgon, J. (1950-1951), "La syntaxe des routiers romains", Bulletin de la Société des Antiquaires de France: 145-154.

Heurgon, M. (1969), "Inscriptions étrusques de Tunisie”, CRAI, 526-551.

Heurgon, M. (1969a), “Les Dardaniens en Afrique”, REL 47: 284-294.

Higbie, C. (2007), "Hellenistic Mythographers", in R. Woodart (ed.), The Cambridge Companion to Greek Mythology, Cambridge, 237-54.

Hignett, C. (1963), Xerxes' Invasion of Greece, Oxford.

Hoffmann, C. (1991), An introduction to bilingualism, London, New York.

Hoffmann, M. (1956), 5000 Jahre Bier, Berlin.

Holban, M., Bulgaru, M. M. A., Cernovodeanu, P. (eds.) (1980-83), Calatori straini despre tarile române (Foreign Travellers about the Romanian Countries), Bucuresti, vol. VII: 1980; vol. VIII: 1983.

Homo, L. (1972), Rome impériale et l'urbanisme dans l'antiquité, Paris.

Hopkinson, N. (1984), “Callimachus' Hymn to Zeus”, CQ 34: 139-148.

Hornblower, S. (2008), A Commentary on Thucydides. Volume I: Books I-III, Oxford - New York.

Houaiss, A. (2001), Dicionário Houaiss da lingua portuguesa, Rio de Janeiro.

Howgego, Chr, Heuchert, V. Burnett, A. (eds.) (2004), Coinage and identity in the Roman provinces, Oxford.

Howgego, Chr. (2004), "Coinage and identity in the Roman provinces", in Chr. Howgego, A. Heuchert y Burnett (eds.), Coinage and identity in the Roman provinces, Oxford, 1-18.

Huizinga, J. (1948), Le déclin du Moyen Âge, Paris.

Hunter, R., Fuhrer, T. (2002), "Imaginary Gods? Poetic Theology in the Hymns of Callimachus", in F. Montanari, L. Lehnus (eds.), Callimaque. Sept Exposés suivis de discussions, Vandoeuvros-Gender, 143-175.

Hurlet, F. (1996), Les collègues du prince au temps d'Auguste et de Tibére: de la légalité républicaine à la légitimité dynastique, Roma.

Hutchinson, G. O. (1988), Hellenistic Poetry, Oxford.

HCT = Gomme, A. J., (1970), A Historical Commentary on Thucydides. vs. 1-2, Oxford. 
Icks, M. (2001), "Priestohood and Imperial Power. The Religious Reforms of Heliogabalus 220-222", in L. de Blois (ed.), Administration, Prosopography and Appointment Policies in the Roman Empire. Proceedings of the First Workshop of the International Network Impact of Empire (Roman Empire, 27 B.C. - A.D. 406), Amsterdam, 169-178.

$I R T=$ Reynolds , J. M., Ward-Perkins, J. B. (1952), Inscriptions of Roman Tripolitania, Rome.

Jackson. K. (1953), Language and history in Early Britain, Edinburgh.

Jacoby, F. (1923), Die Fragmente der griechischen Historiker, Part I-III, Berlin.

Jaeger, W. (s.d), Paideia, Trad. de Artur M. Parreira, São Paulo.

Janko R. (1982), Homer, Hesiod and the Hymns, Cambridge.

Jiménez, A. J. (1995), "La imagen de Teseo en las Suplicantes", in J. A. López Férez (ed.), De Homero a Libanio, Madrid, 145-161.

Johnson, L. (1960), "Natalis urbis and principium anni", TPAPhA 91: 109-120

Julia, D. (1962), "Les monuments funéraires en forme de demi-cylindre dans la province romaine de Tarragonaise", MCVI : 29-54.

Jullian, C. (1926), "Notes gallo-romaines”, Rérue des Études Anciennes 28. 2: 139-151.

Little, K. (2002), "Monasticism and Western Society: from marginality to the establishment and back", Memoirs of the American Academy in Rome 47: 83-94.

Kaimio, J. (1979), The Romans and the Greek Language, Helsinki.

Kalinowski, A. (2007), "A series of honorific statue bases for the Vedii in the market agora at Ephesos (IvE 725, 731, 3076-3078)", in M. Mayer, G. Baratta, A. Guzmán, (eds.), Acta XII Congressus internationalis epigraphiae Graecae et Latinae. Provinciae imperii Romani inscriptionibus descriptae, vol I, Barcelona, 757-762.

Kantiréa, M. (2007), Les dieux et les dieux augustes. Le culte impérial en Grèce sous le Julio-claudiens et les Flaviens, Études épigraphiques et archéologiques, Athènes.

Katz, S. H., Fleming, S. J., McGovern, P. E. (1996), The origins and ancient history of wine. Food and nutrition in history and anthropology 11, Amsterdam.

Kelso W.M. (ed.) (1990), Earth patterns. Essays in landscape archaeology, Charlottesville.

Kerkhecker, A. (1999), Callimachus' Book of "Iambi", Oxford.

Khanoussi, M. (1983), “Nouvelles sépultures d'époque romaine”, in Beschaouch A. et alii (eds.), Recherches archéologiques franco-tunisiennes à Bulla-Regia, I (CEFR 28/I), Roma, 93-106.

Kiss, Z. (1975), L'iconographie des princes julio-claudiens au temps d'Auguste et de Tibère, Varsovie. 
Kleiner, F. S. (1991), "The trophy on the bridge and the Roman triumph over nature", L'Antiquité Classique 60: 182-192.

Koch, J. (2009), Tartessian. Celtic in the South-west at the dawn of history, Aberystwyth.

Koch, J. (2009a), "A case for Tartessian as a Celtic language", Palaeohispanica 9: 339-351.

Kolb, A. (2001), "Tansport and communication in Roman state: the cursus publicus", in C. Adams and R. Laurence (eds.), Travel and Geography in the Roman Empire, Londres - Nova Iorque, 95-105.

Kolb, A. (ed.) (2010), Augustae. Machtbewusste Frauen am römischen Kaiserhof? Herrschaftsstrukturen und Herrschaftspraxis, Berlin.

Kozakai, T. (2000), L'étranger, l'identité. Essai sur l'integration culturelle, Paris.

Kramer, N., Reitz, Chr. (eds.) (2010), Tradition und Erneuerung. Mediale Strategien in der Zeit der Flavier, Berlin, New York.

Kristeller, P. O. (1961, 3a ed.), “The moral thought of Renaissance humanism”, in Chapters in Western civilization, I, New York, 289-335.

Krynen, J. (1981), Idéal du prince et pouvoir royal en France à la fin du Moyen Âge (1380-1440). Étude de la littérature politique du temps, Paris.

Kuhoff, W. (2001), Diokletian und die Epoche der Tetrarchie, Frankfurt.

Künzl, S. (1997), Die Trierer Spruchbecherkeramik. Dekorierte Schwarzfirniskeramik des 3. und 4. Jahrbunderts (Beihefte Trierer Zeitschrift 21), Trier.

Lambert, P. Y. (1994), La langue gauloise, Clamecy.

Lambrino, S. (1937), "La famille d'Apollon à Histria”, Aephem 100: 352-362.

Lambrino, S. (1952), "Les inscriptions de São Miguel de Odrinhas”, Bulletin des Études Portugaises 16: 134-176.

Lasserre, F. (1976), "Hérodote et Protagoras: le débat sur les constitutions", $M H$ 33: 65-84.

Lateiner, D. (1984), "Herodotean historiographical patterning: the constitutional debate", QS 20: 257-284.

Laurence, R. (2001), "Afterword: travel and empire", in C. Adams and R. Laurence (eds.), Travel and Geography in the Roman Empire, Londres / Nova Iorque, 167-176.

Lausberg, H. (1990, 3a ed.), Handbuch der literarischen Rhetorik. Eine Grundlegung der Literaturwissenschaft, Stuttgart.

Lawrance, J. N. H. (1990), "Humanism in the Iberian Peninsula", in A. Goodman, A. Mackay (eds.), The Impact of Humanism on Western Europe, Londres, 220-258.

Lazenby, J. F. (1993), The Defence of Greece, 490-479 B.C., Warminster. 
Leão, D. F. (2012), A Globalização no Mundo Antigo. Do Polites ao Kosmopolites, Coimbra.

Lehmann, K. (1962), "Ignorance and search in the villa of the Mysteries", JRS 52: $62-68$.

Leite de Vasconcelos, J. (1913), Religióes de Lusitania, III, Lisboa 1989.

Leite, S. (ed.) (1963), Estatutos da Universidade de Coimbra (1559), Coimbra.

Lekai, L. J. (1987), Los Cistercienses. Ideales y realidad, Barcelona.

Lemny, S. (2010), Cantemirestii. Aventura europeana a unei familii princiare din secolul al XVIII-lea (Les Cantemir: l'aventure européenne d'une famille princière au XVIIIe siècle, 2006), Iasi, Polirom.

Lesky, A. (1995), História da Literatura Grega, Lisboa.

Leveau, Ph. (1992), "Le territoire agricole d'Arles dans l'antiquité. Relecture de l'histoire économique d'une cité antique à la lumiere d'une histoire du milieu”, in M. Bernardi (cur.), Archeologia del Paesaggio, Firenze, vol. II, 597-636.

Levy, A. M. (2010), Sex Acts in Early Modern Italy: Practice, Performance, Perversion, Punishment, Farnham.

Lewis, D. M, Boardman, J., Hornblower, S., Ostwald, M (eds.) (1994), The Cambridge Ancient History, Volume 6: The Fourth Century BC, Cambridge.

Lewis, D. M. (1994), “The Athenian Tribute Quota Lists, 453-450 BC”, BSA 89: 285-301.

Lima, D. C. (1998, 3a ed.), Câmara Cascudo: um brasileiro feliz. Rio de Janeiro.

Lintott, A. (1992), Judicial reform and land reform in the Roman Republic, Cambridge.

Little K. (2002), "Monasticism and Western Society: from marginality to the establishment and back", Memoirs of the American Academy in Rome 47: 83-94.

Littman, R. J. (1974), The Greek experiment, Imperialism and social conflict 800400 B. C., Londres.

Liverani, P. (1994), "Il ciclo di ritratti del edificio absidato a Roselle", in Roselle: iconografia imperiale e glorificazione Familiare, MDAI, RA 101: 161-163.

Loeschcke, S. (1932), "Römische Denkmäler vom Weinbau an Mosel, Saar und Ruwer", TrZ 7: 42-60.

Loeschcke, S. (1933), Denkmäler vom Weinbau aus der Zeit der Römerherrschaft an Mosel, Saar und Ruwer, Trier.

López Moreda, S. (2009), Aulo Gelio, Noches Aticas, Madrid.

López Vilar, J. (1999-2000), “Consideracions sobre les cupae i altres estructures funeràries afins”, Bullettí Arcqueològic V. 21-22: 65-103. 
Lorenzo Gómez, F. (2010), Un dios entre los hombres. La adoración a los emperadores romanos en Grecia, Barcelona.

Losada Goya, J. M. (ed.) (2010), Mito y Mundo contemporáneo. La recepción de los mitos antiguos, medievales y modernos en la litetatura contemporânea, Bari.

Lucet, B. (1977), Les codifications cisterciennes de 1237 et de 1257, Paris.

Macan, R.W. (1908), Herodotus, The Seventh, Eighth, E Ninth Books, London.

Machado de Assis, J. M. (1971), "Esaú e Jacó", in Machado de Assis, Obra Completa, Rio de Janeiro, José Aguilar Editora.

Maehler, H. (1982), Die Lieder des Bakchylides I (2 vols.), Leiden.

Magioncalda, A. (1991), Lo sviluppo della titolatura imperiale da Augusto a Giustiniano attraverso le testimonianze epigrafiche, Torino.

Magueijo, C. (1970), “A Lex Metallis Dicta”, O Arqueólogo Português série 3, 4: 125-163.

Maltese, V. E.-Cortassa, G. (eds.)(2000), Roma parte del cielo. Confronto tra l'Antica e la Nuova Roma di Manuele Crisolora, Torino.

Mamede, Z. (1970), Luis da Câmara Cascudo: 50 anos de vida intelectual 1918/1968, Natal.

Manconi, D., Catalli, F. (eds.) (2005), Le immagini del potere. Il potere delle immagini. L'uso del ritratto ufficiale nel mondo romano da Cesare ai Severi, Perugia.

Mann, C. (2001), Athlet und Polis im archaischen und frübklassischen Griechenland, Göttingen.

Mantas, V. G. (2008-2009), "A rede viária romana em Portugal. Estado da questão e perspectivas futuras", Anas 21-22: 245-272.

Mantas, V. G. (2011), "Linhas fortificadas e vida quotidiana: da Muralha da China à Muralha do Atlântico", in C. Guardado da Silva (coord.), A Vida quotidiana nas Linhas de Torres Vedras, Torres Vedras, 15-56.

Mantas, V. G. (2012), As vias romanas da Lusitânia, Mérida.

Maquiavel, N. (2010, 8ª ed), O principe, Trad. de Pietro Nassetti, Martin Claret, São Paulo.

Maquiavel, N. (1980), Le Prince de Maquiavel, Traduction et commentaire de C. Roux-Lehman, Paris.

Maravall, J. A. (1972), Estado moderno y mentalidad social (siglos XV a XVII), 2 vols., Madrid.

Marco, F. (1993), "Nemedus Augustus", in I. J. Adiego, J. Siles, J. Velaza, (eds.), Studia Palaeohispanica et Indogermanica J. Untermann ab amicis Hispanicis oblata, Barcelona, 163-178. 
Marco, F. (1996), "Integración, interpretatio y resistencia religiosa en el occidente del imperio", in J. M. Blásquez, J. Alvard (ed.) La romanización en Occidente, Madrid, 217-238.

Marcos Casquero, M. A., Domínguez García, A. (2006), Aulo Gelio, Noches Áticas, vol. I, Universidad de León.

Marcy, G. (1936), Les inscriptions libyques bilingues de l'Afrique du nord, Paris.

Moreno Gallo, I. (2006),Vias romanas: ingenieria y técnica constructiva. Madrid.

Marlière, É. (2001), Le tonneau en Gaule Romaine», Gallia 58: 181-201.

Marlière, É. (2002), L'outre et le tonneau dans l'Occident romain, Montagnac.

Marques, M. A. F. (1998), "A introdução da Ordem de Cister em Portugal”, in Estudos sobre a Ordem de Cister em Portugal, Lisboa.

Marrou, H.-I. (1963), "L'Église dans la première moitié du quatrième siècle”, in L'Église de l'Antiquité tardive 303-604, Paris, 26-35.

Marrou, H.-I. (1965, 6ª ed.), Histoire de l'éducation dans l' Antiquité, Paris.

Marshall, P. K (1983), "Aulus Gellius", in L.D. Reynolds (ed.), Texts and Transmission. A Survey of the Latin Classics, Oxford.

Martínez, A. (1993), "Dos esgrafiados ibéricos sobre una estela romana de Requena (Valencia)", Saguntum 26: 247-251.

Martínez-Pinna, J. (2002), "Los arcadios", in La prebistoria mitica de Roma, Gerión. Anejos 6: 135-167.

Martini, W. (1990), Die archäischen Plastik der Griechen, Darmstadt.

Mastino, A. (1981), Le titolature di Caracalla e Geta attraverso le iscrizioni (indici), Bolonia.

Mattoso, A., (1935 2a ed.), Compêndio de história antiga, Sá da Costa, Lisboa.

Maurice, F. (1930), "The Size of the Army of Xerxes in the Invasion of Greece 480 B.C.", JHS 50: 210-35.

Mayer, M. (1980), "La plasmación lingüística de la pervivencia de los cultos prerromanos en Hispania a través de los formularios epigráficos", Revista Española de Lingüistica 10: 230-231.

Mayer, M. (1993), "El paganismo cívico de los siglos II y III en la Hispania citerior. Su reflejo en la epigrafía", in Ciudad y comunidad civica en Hispania. Siglos II y III d. C. Cité et communauté civique en Hispania, Madrid, 161-175.

Mayer, M. (1995), "El primer horizonte epigráfico en el litoral noreste de la Hispania citerior", in F. Beltrán (ed.), Roma y el nacimiento de la cultura epigráfica en Occidente, Zaragoza, 97-119.

Mayer, M. (1998), “¿Qué es un Augusteum?, Historia Antiqua 4: 63-70.

Mayer, M. (1999), “Aproximación a la religión cívica en Hispania bajo los 
flavios", Ktema 24: 341-345.

Mayer, M. (2004), "El Augusteum de Narona (Vid, Metković, Croacia) en época de los Severos", in Orbis Antiquus. Studia in honorem Ioannis Pisonis, ClujNapoca, 283-289.

Mayer, M. (2005), "Constantino el Grande: deconstrucción y construcción de un Imperio", in F. de Oliveira (coord.), Génese e Consolidação da Ideia de Europa, vol. III, O Mundo Romano, Coimbra, 203-230.

Mayer, M. (2007a), "La presenza imperiale nelle città del Picenum tra l'epoca augustea e il regno dei Severi : un primo aproccio", Studi Maceratesi 41: 27-40.

Mayer, M. (2007b), "Las dedicatorias a miembros de la domus Augusta julio-claudia y su soporte: una primera aproximación”, in G. Paci (ed.), Contributi all'epigrafia del'età augustea. Actes de la XIII' Rencontre francoitalienne sur l'épigraphie du monde romain, Tivoli, 171-199

Mayer, M. (2008), "Sila y el uso político de la epigrafía", in M. Caldelli, G. L. Gregori, S. Orlandi (eds.), Epigrafia 2006. Atti della XIVerencontre sur l'épigraphie in onore di Silvio Panciera con altri contributi di colleghi, allievi e collaboratori, Roma, 121-135.

Mayer, M. (2009), "Los honores recibidos por la familia de Marco Aurelio en la parte oriental del imperio romano: ¿̨cambio o continuidad en el culto dinástico?", in A. Martínez Fernández (ed.), Estudios de Epigrafía Griega, La Laguna, 277-294.

Mayer, M. (2010), "La presència de la dinastia antonina a Tarraco", in Studia Celtica Classica et Romana Nicolae Szabó septuagesimo dicata, Budapest, 159-167.

Mayer, M. (2015), "La epigrafia y el Augusteum de Narona", in G. Zecchini (ed.), L 'Augusteum di Narona. Atti della Giornata di Studi. Roma 31 maggio 2013, (Centro ricerche e documentazione sull' antichità clàssica, monografie, 3 7), Roma, pp. 19-41.

McCrum, M., Woodhead, A.G. (1961), Select Documents of the Principates of the Flavian Emperors Including the Year of Revolution, A.D. 68-96, Cambridge.

Mednikarova, I. (2003), "The accusative of the name of the deceased in Latin and Greek epitaphs", ZPE 143: 117-134.

Meiggs, R. (1972), The Athenian Empire, Oxford.

Melani, V., Vergari, M. (1985), Profilo di una città etrusca Roselle, Pistoia.

Melchor Gil, E. (1992), "Sistemas de financiación y medios de construcción de la red viaria hispana”, Habis, 23: 121-137.

Melchor Gil, E. (2010), "Homenajes estatutarios e integración de la mujer en la vida pública municipal de las ciudades de la Bética", in F. J. Navarro (ed.), Pluralidad e integración en el Mundo Romano, Pamplona, 221-245. 
Mellor, R. (1975), ӨEA P $\Omega$ MH the Worship of the Goddess Roma in the Greek World, Göttingen.

Mellor, R. (1981), “The Goddess Roma”, in $A N R W$ II 17. 2, Berlin, New York, 950-1030

Menegazzi, L. (1995), Il manifesto italiano (prima ed. 1974), Milano.

Merêa, P. (1929), História de Portugal, Vol. II. Coimbra.

Merêa, P. (1941), Suárez, Grácio, Hobbes, Coimbra.

Mesnard, P. (1977), Essor de la philosophie politique au XVIe Siècle, Paris.

Messerschmidt, W. (2003), Prosopopoiia: Personifikationen politischen Charakters in spätklassischer und hellenistischer Kunst, Köln.

Michelini, A. N. (1994), "Political themes in Euripides' Suppliants", AJPh 115. 2: $219-252$.

Millar, F. (1968), "Local cultures in the Roman Empire: Libyan, Punic and Latin”, JRS 58: 126-134.

Millar, F. (1993), The Roman Near East 31 BC-337 AD, London.

Millar, F. (2006), A Greek Roman Empire, Power and belief under Theodosius II 408-450, Berkeley.

Minerath, R. (1996), Histoire des Conciles, Paris.

$M L H=$ J. Untermann, J. (1975-2000), Monumenta linguarum Hispanicarum, $\mathrm{I}-\mathrm{V}$, Wiesbaden.

Moggi, M. (1976), I sinecismi interstatali greci, Pisa.

Moncada, C. (1947), Filosofia do direito e do estado, I, Coimbra.

Monfrin, J. (1964), "Humanisme et traductions au Moyen Age", in L'Humanisme médieval dans les littératures romanes du XIIe au XIVe siècle (Actes du Colloque organisé par le Centre de Philologie et de Littératures romanes de l'Université de Strasbourg), Paris.

Monteiro, N., d'Encarnação, J. (1993-1994), “A propósito de uma inscrição latina em Santiago da Guarda (Ansião)", Conimbriga 32-33: 303-311.

Moretti, G. (2007), "Patriae trepidantis imago. La personificazione di Roma nella Pharsalia fra ostentum e disseminazione allegorica", Camenae 2: 1-17

Morrison, A. D. (2007), The Narrator in Archaic Greek and Hellenistic Poetry, Cambridge.

Mosley, D. J. (1965), "The Size of Embassies in Ancient Greek Diplomacy”, ТРАРЬA: 255-266.

Mosley, D. J. (1972), "Envoys and diplomacy in Ancient Greece”, Historia 22: 1-97.

Mossé, Cl. (1970), La colonisation dans l'Antiquité, Paris, 27-99. 
Mullen, A. (2007), “Linguistic evidence for 'romanization': continuity and change in Romano-British onomastics: a study of the epigraphic record with particular reference to Bath", Britannia 38: 35-61.

Muñoz, V. (2005), "La interpretatio romana del dios prerromano Bandue", Veleia 22: $145-152$.

Munro, J.A.R. (1926), “Xerxes' Invasion of Greece”, in The Persian Empire and the West, Cambridge Ancient History, Vol. IV, Cambridge, 268-316.

Nascimento, A. A. (1990), "Poggio e o seu interesse por códices de Alcobaça", Revista da Faculdade de Letras de Lisboa 13-14: 37-40.

Nascimento, A. A. (1993), "As librarias dos príncipes de Avis", Biblos. Revista da Faculdade de Letras (Coimbra). Actas do Congreso Comemorativo do $6^{\circ}$ Centenário do Infante D. Pedro (25 a 27 de Novembro de 1992) 69: 265-287.

Nascimento, A. A. (1995), "La réception des auteurs classiques dans l'éspace cultural portugais: une questione ouvert", in C. Leonardi, B. Munk Olsen (eds.), The Classical Tradition in the Middle Ages and Renaissance, Spoleto, 47-56.

Nascimento, A. A. (1997), "Traduzir, verbo de fronteira nos contornos da Idade Média”, in C. Almeida Ribeiro, M. Madureira (eds.), O género do texto medieval, Lisboa, 113-138.

Nascimento, A. A. (1999), Cister. Os documentos primitivos. No 9.० Centenário da fundação de Cister (1999). Introdução, tradução e notas de Aires A. Nascimento, Lisboa.

Navarro Caballero, M. (2003), "Mujer de notable: representación y poder en las ciudades de la España imperial”, in S. Armani, B. Martineau-Hurlet, A. U. Stylow, (eds.), Acta antiqua Complutensia IV. Epigrafía y sociedad en Hispania durante el Alto Imperio: estructuras sociales, Alcalá de Henares, 119-127.

Nemeti, S. (1998), "Cultul lui Sucellus-Dis Pater şi al Nantosueltei-Proserpina în Dacia romană”, EphemNapoc 8: 95-121.

Neumann, G., Untermann, J. (eds.) (1980), Die Sprachen im Römischen Reich der Kaiserzeit. Beihefte der Bonner Jabrbücher 40, Bonn.

Nicosia, F. (ed.) (1990), Un decennio di ricerche a Roselle. Statue e ritratti, Firenze.

Nunes, E., Albuquerque, M. (1968), "Parecer do doutor 'Valasco di Portogallo' sobre o beneplácito régio (Florença, 1954)”, in V. Rau (ed.), Do tempo e da bistoria, Lisboa, t. 2, 97-139.

Ober, J. (1989), Mass and Elite in Democratic Athens. Rhetoric, Ideology, and the Power of the People, Princeton.

Odiot, T. (2004), "Le site du Molard à Donzère", in Brun, J.-P., Poux, M., Tchernia, A. (eds.), Le vin. Nectar des Dieux. Génies des Hommes, Gollion, 202-203. 
Oelmann, F. (1914), Die Keramik des Kastells Niederbieber, Frankfurt.

Ohly, D. (1976), Die Aegineten: die Marmorskulpturen des Tempels der Aphaia auf Aegina. (a) I. Die Ostgiebelgruppe. München. (b) II. Die Westgiebelgruppe. III. Altarplatzgrupen, Akrotere, etc, München.

Olteanu, T. (2008), "El culto a Victoria y la interpretatio indígena en el Occidente de Hispania, Gallia y el norte de Britania", BVallad 74: 197-224.

Ors, A. de (1953), Epigrafia juridica de la España romana, Madrid.

Pacaut, M. (1993), Les moines blancs. Histoire de l'Ordre de Cîteaux, Paris.

Pallottino, M. (1952), "El problema de las relaciones entre Cerdeña e Iberia en la antigüedad prerromana", Ampurias 14: 137-155.

Panciera, S. (2003), "Umano, sovraumano o divino? Le divinità augustee e l'imperatore a Roma", in L. de Blois, P. Erdkamp, O. Hekster, G. De Kleijn, S. Mols, (eds.), The Representation and Perception of Roman Imperial Power. Proceedings of the Third Workshop of the International Network Impact of Empire (Roman Empire c. 200 B.C. - A.D. 476), Amsterdam, 219-239.

Paparelli, G. (1973), Feritas, humanitas, diuinitas. L'essenza umanistica del Rinascimento, Napoli.

Parker, V. (1988), "Túpavvoc. The semantics of a political concept from Archilochus to Aristotle", Hermes 126. 2: 145-172.

Patillon, M. (ed.) (2002), Pseudo-Aelius Aristide, Arts rhétoriques, Paris.

Pekary, T. (1968), Untersuchungen zu den römischen Reichsstraßen, Bona.

Pellegrini, D. P. M. (2003), Le Grandi Storie dell'Auto, vol. 2, Alfa Romeo, 35-35.

Pelling, Ch. (2002), "Speech and action: Herodotus' Debate on the Constitutions", PCPhS 48: 123-158.

Peña Cervantes, Y. (2010), Torcularia. La producción de vino y aceite en Hispania. Catálogo de yacimientos analizados en cedé (Sèrie documenta 149), Tarragona.

Pensa, M. (1979), "Genesi e svilupo dell'arco onorario nella documentazione numismática”, Studi sull'Arco Onorario Romano, Roma, 19-27.

Peres, D. (1952), História de Portugal, II, Porto.

Pérez Martin, A. (1979), Proles Aegidiana. I. Introducción. Los Colegiales desde 1368 a 1500 , Bolonia.

Pérez Martin, A. (1999), Españoles en el Alma Mater Studiorum. Profesores hispanos en Bolonia (de fines del siglo XII a 1799), Murcia.

Pérez Ruiz, F. (1984), "El justo es feliz y el injusto desgraciado, justicia y felicidad en la República de Platon", Pensamiento 40, 159: 257-295.

Petrarca, F. (1581), Francisci Petrarchae Florentini Opera. Basileae, per Sebastianum Henricpetri. 
Petrarca, F. (1942), Epistolae familiares, in V. Rossi (ed.), Le Familiari, Firenze.

Petri, Ch. (1989), 'La politique de Constance II: un premier 'césaropapisme' ou l'imitatio Constantini?", in A. Dihle (coord.), L'église et l'empire au IV siècle, Genève, 113-178.

Pfeiffer, R. (1949-1951), Callimachus, 2 vols., Oxford.

Pflaum, H.G. (1976), Inscriptions latines de l'Algérie, t. II, vol. II, Inscriptions de la Confédération cirtéenne, de Cuicul et de la tribu des Suburbures, Alger.

Pflug, H. (1941), As auto-estradas do Reich, Berlim.

Pharr, C. et alii (2008), The Theodosian Code and Novels and the Sirmondian Constitution. Translation, commentary and bibliography, Union (NJ).

Piana, C. (1976), Nuovi documenti sull'Universitá di Bologna e sul Collegio di Spagna,I-II, Bolonia, Zaragoza.

Pick, B. (1898), Die antiken Münzen Nordgriechenlands I, 2. Die antiken Münzen von Dacien und Moesien, Berlin.

Piganiol, A. (1972, 2a ed.), L'empire chrétien, Paris.

Pina, R. de (1977), Chronica do Senhor Rey D. Affonso V, cap. CXXV "Das feiçoões custumes e virtudes do Yfante Don Pedro”, in M. L. de Almeida (Intro. e Revisão), Crónicas de Rui de Pina, Porto.

Pinheiro Futre, M. P. (2006), "Do Mito à Utopia: viagem ao mundo do imaginário grego" in Actas do V Congresso da APEC-Antiguidade Clássica e nós: Herança e Identidade Cultural, Braga, 569-581.

Pinho, S. T. (1999), "Os Príncipes de Avis e o Pré- Humanismo Português", in Raizes Greco-Latinas da Cultura Portuguesa. Actas do I Congresso da APEC, Coimbra, 99-133.

Pinto, Frei H. (1952), "Diálogo da justiça”, in Imagem da vida cristã, I, Lisboa.

Pippidi, D. M. (1971), I Greci nel Basso Danubio dall'età arcaica alla conquista romana, Mailand.

Pirling, R. (1993), "Ein Trierer Spruchbecher mit ungewöhnlicher Inschrift aus Krefeld-Gellep", Germania 71: 387-404.

Podlecki, A. J. (1976), “Athens and Aegina”, Historia 25.4: 396-413.

Poenaru Bordea, G. (1979), "Les statères ouest-pontiques de type Alexandre le Grand et Lysimaque”, RBNS 125: 37-51.

Prag, J. R. W. (2002), "Epigraphy by numbers: Latin and the epigraphic culture in Sicily", in A. E. Cooley (ed.), Becoming Roman, Writing Latin? Literacy and Epigraphy in the Roman West. JRA Suppl. Ser. 48: 15-31.

Preda, C., Popescu, E., Diaconu, P. (1962), "Săpăturile arheologice de la Mangalia (Callatis)", Materiale 8: 439-455.

Pressouyre, L. (1990), Le rêve cistercien, Paris. 
Price, S. R. F. (1984), Rituals and Power. The Roman Imperial Cult in Asia Minor, Cambridge.

Privitera, G. A. (1988), "Pindaro, Nem. III 1-5 e l'acqua di Egina”, QUCC 58: 63-70.

Puerta Torres, C. (1995), Los miliarios de la Vía de la Plata, 1-2, Madrid.

Quadrino, D. (2007), Una nuova iscrizione onoraria di Adriano e il Sebasteion di Kestros in Cilicia Tracheia, Tivoli.

Radnoti Alföldi, M., Rasbach, G. (1999), "Zur Frage der interpretatio Romana“, in Festschrift für Günter Smolla, Wiesbaden, 597-605.

Raepsaet-Charlier, M. Th. (1975), "La datation des inscriptions latines dans les provinces occidentales de l'Empire Romain d'après les formules " In $\mathrm{H}$ (onorem) D(omus) D(ivinae) » et «Deo, Deae »", in ANRW II 3: 232-282.

Raepsaet-Charlier, M. Th. (2005), "Les sacerdoces des femmes sénatoriales sous le Haut-Empire", in M.-F. Baslez, F. Prévot (eds.), Prosopographie et histoire religieuse. Actes du colloque tenu en l'Université Paris XII-Val de Marne le 27 E 28 octobre 2000, Paris, 283-304.

Ramalho, A. C. (1985), Latim Renascentista em Portugal (Antologia), Coimbra.

Rapp, Cl. (2005), Holy Bishops in Late Antiquity, The nature of Christian Leadership in an age of transition, Berkeley.

Rau, V. (1969), "Italianismo na cultura jurídica portuguesa do século XV", Revista Portuguesa de História 12.1: 185-206.

Rau, V. (1973), "Studenti ed eruditi portoghesi in Italia nel secolo XV", Estudos Italianos em Portugal 36: 7-73.

Rawlinson, H. G. (1916), Intercourse between India and the Western World from the Earliest Times to the Fall of Rome, Cambridge.

Rebelo, D. L. (1951), Do governo da republica pelo rei (de republica gubernanda per regem), reprodução fac-similada da edição de 1496, Introdução e notas de A. M. de Sá, Lisboa.

Rebelo, L. de S. (1983), A concep̧̣ão do poder em Fernão Lopes, Lisboa.

Rebuffat, R. (2007), "Pour un corpus des bilingues punico-libyques et latinolibyques", in M. H. Fantar (ed.), Osmose etnho-culturelle en Méditerranée, Tunis, 183-242.

Regra do Patriarca S. Bento (1992), Edições “Ora \& Labora”, Singeverga.

Rhodes, P. J. (1993), A Commentary on the Aristotelian ATHENAION POLITEIA, Oxford.

Rhodes, P. J. (2006), A History of the Classical Greek World 478-323 BC, Molden. RIB = Collingwood, R. G. (1965), The Roman inscriptions of Britain. I. Inscriptions on stone, Oxford. 
RIG = P.-M. Duval (ed.), Recueil des inscriptions gauloises, Paris 1985-. I: M. Lejeune, Textes gallo-grecs, 1985; II.1: M. Lejeune, Textes gallo-étrusques. Textes gallo-latins sur pierre, 1988; II.2: P.-Y. Lambert, Textes gallo-latins sur instrumentum, 2002; III: P.-M. Duval y G. Pinault, Les calendriers (Coligny, Villards d'Héria), 1988; IV: J.-B. Colbert de Beaulieu y B. Fischer, Les légendes monétaires, 1998.

Ripollés, P. P. (2004), "Coinage and identity in the Roman provinces: Spain", in Ch. Howgego, V. Heuchert, A. Burnett (eds.), Coinage and identity in the Roman provinces, Oxford, 79-93.

Ripollés, P. P., Velaza, J. (2002), "Saguntum, colonia latina”, ZPE 141: 285-294.

Rodgers, B. (1989), “The Metamorphosis of Constantine”, CQ 39.1: 233-246.

Rodrigues, M. A. (1993), "O infante D. Pedro e a Universidade”, Biblos. Revista de Faculdade de Letras (Coimbra). Actas do Congreso Comemorativo do $6^{\circ}$ Centenario do Infante D. Pedro (25 a 7 de Novembro de 1992) 69: 345362.

Rodrigues, N. S. (2007), "Entre Europa e Io: elementos orientais na arte grega arcaica e clássica", in J. A. Ramos, L. M. Araújo, A. Ramos dos Santos (eds.), Arte Pré-Clássica. Colóquio Comemorativo dos Vinte Anos do Instituto Oriental da Faculdade de Letras da Universidade de Lisboa, Lisboa, 323346.

Rodríguez, P., Díez de Pinos, E. (2014), "Nueva inscripción celtibérica en piedra de E1 Pueyo de Belchite (Zaragoza)", Palaeohispanica 14: 245-262.

Rodríguez Colmenero, A., Ferrer Sierra, S., Álvarez Asorey, R. (2004), Miliários e outras inscricións viarias romanas do noroeste hispánico. Santiago de Compostela.

Rocha Pereira, M. H. (1981), "O mais antigo texto europeu de teoria política", Nova Renascença 1: 364-370.

Rocha Pereira, M. H. (1990), “O 'Diálogo dos Persas’ em Heródoto”, Estudos Portugueses. Homenagem a António José Saraiva, Lisboa, 351-362.

Rocha Pereira, M. H. (2003), Hélade. Antologia da Cultura Grega, Asa, Porto.

Rocha Pereira, M. H. (2008, 8a ed.), Sófocles: Antígona, Coimbra.

Roha Pereira, M. H. (2009, 10ª ed.), Hélade, Lisboa, Guimarães.

Rocha Pereira, M. H. (2012), Estudos de História da Cultura Clássica, vol.1 Cultura Grega, Lisboa.

Roldán Hervás, J. (1975), Itineraria Hispana. Fuentes antiguas para el estudio de las vías romanas en la Peninsula Ibérica, Madrid.

Röllig, W. (1980), “Das Punische im Römischen Reich”, in G. Neumann, J. Untermann (eds.), Die Sprachen im Römischen Reich der Kaiserzeit. (Bonner Jabrbücher des Rheinischen Landesmuseums in Bonn im Landschaftsverband 
Bibliografia

Rheinland und des Vereins von Altertumsfreunden im Rheinlande 40), Köln, 285-299.

Romano, E. (2006-2009), "Le tombe "a cupa" in Italia e nel Mediterraneo. Tipologia architettonica, committenza e rituale”, StClOr 52: 149-219.

Romilly, J. de (1959), "Le classement des constitutions d'Hérodote à Aristote", REG 72: 81-99.

Rose, C. B. (1997), Dynastic Commemoration and Imperial Portraiture in the Julio-Claudian Period, Cambridge.

Rosenthal, F. (1936), Die Sprache der palmyrenischen Inschriften und ibre Stellung innerhalb des Aramäischen, Leipzig.

Rosivach, V. J. (1977), "Earthborns and Olympians: the parodos of the Ion", CQ 27. 2: 284-294.

Rosivach, V. J. (1988), "The Tyrant in Athenian Democracy", QUCC 59: 43-57.

Rossillon, Ph. (ed.) (1995), Atlas de la langue française, Paris.

Rossiter, J. J. (1978), Roman Farm Buildings in Italy (BAR int. Ser. 52), Oxford.

Rössler, O. (1980), "Libyen von der Cyrenaica bis zur Mauretania Tingitana", in G. Neumann, J. Untermann (eds.), Die Sprachen im Römischen Reich der Kaiserzeit. (Bonner Jabrbücher des Rheinischen Landesmuseums in Bonn im Landschaftsverband Rheinland und des Vereins von Altertumsfreunden im Rheinlande 40). Köln, 267-284.

Rubenstein, L. (2004), "Ionia", in M. H Hansen, T. H. Nielsen (eds.), An Inventory of Archaic and Classical poleis, Oxford, 1053-1107.

Rucquoi, A. (2003), "Rois et princes portugais chez les auteurs castillans du $\mathrm{XV}^{\mathrm{e} m e}$ siécle», Península. Revista de Estudos Ibéricos. Entre Portugal e Espanha. Relaçôes Culturais (sécolos XV-XVIII). In Honorem Jose Adriano de Freitas Carvalho, 0: 39-51.

Ruggini, L. C. (1989), "Felix Temporum Reparatio", in A. Dihle (coord.), Realtà socio-economiche in movimento durante un ventennio di regno (Costanzo II Augusto, 337-361 d.C.), L'église et l'empire au IV siècle, Genève, 179-243.

Rüpke, J. (2005), Fasti sacerdotum. Die Mitglieder der Priesterchaften und das sakrale Funktionspersonal römischer, griechischer, orientalischer und jüdischchristlicher Kulte in der Stadt Rom von 300 v. Chr. bis 499 n. Chr., Wiesbaden.

Rusjaeva, A., Vinogradov, Ju. G., (2000), "Apollon Ietros. Herrscher von Istros”, in A. Avram, M. Babeş (eds.), Olbia, Civilisation grecque et cultures antiques périphériques. Hommages à P. Alexandrescu à son $70^{\circ}$ anniversaire, Bucarest, 229-234.

Rutishauer, B. (2012), Athens and the Cyclades. Economic Strategies 540-314 BC, Oxford. Sabbadini, R. (1905), Le scoperte dei codici latini e greci ne' secoli XIV e XV , Florencia. 
Sabbadini, R. (1914), Le scoperte dei codici latini e greci ne' secoli XIV e XV, Florencia.

Saddington, D.B. (1999), "Roman soldiers, local gods and interpretatio Romana in Roman Germany", ActaCl 42:155-169.

Salazar, A. M. (1976), "El impacto humanístico de las misiones diplomáticas de Alonso de Cartagena en la Corte de Portugal entre medievo y renacimiento (1421-31)", in A. D. Deyermond (ed.), Medieval Hispanic Studies presented to Rita Hamilton, Londres, 215-226.

Salinas, M. (1995), "Los inicios de la epigrafía en Lusitania oriental", in F. Beltrán (ed.), Roma y el naámiento de la cultura epigráfica en Occidente, Zaragoça, 281-291.

Salway, B. (2001), "Travel, Itineraria and Tabellaria", in C. Adams and R. Laurence (eds.), Travel and Geography in the Roman Empire, Londres, Nova Iorque, 22-66.

Santo Agostinho (2009 12a ed. ), A cidade de Deus, trad. de Oscar Paes Leme, 2 v., Vozes, Petrópolis, São Paulo.

Santos, M. J. A. (1998), Vida e morte de um mosteiro cisterciense. S. Paulo de Almaziva - Séculos XIII-XV, Lisboa.

Saumagne, C. (1928), "Iter populo debetur", Révue d'Histoire, de Littérature et d'Histoire Anciennes 54: 320-353.

Scheer, T. S. (2003), "The Past in na Hellenistic Present: Myth and Local Tradition", in A. Erskine (ed.), A Companion to the Hellenistic World, Oxford, 216-231.

Scheid, J. (2015), "Les Augustea et le culte des empereurs. Réflexions sur les rites célébrés dans ces lieux de culte", in P. Gros, E. Marin, M. Zink (eds.), Auguste, son époque et l 'Augusteum de Narona. Actes du colloque organisé à l'Académie des Inscriptions et Belles-Letres et l'Université Catholique de Croatie (Zagreb) 12 décembre 2014, 17-30, Paris.

Schilardi, G. (ed.) (1997), Filostrato. Immagini, Lecce.

Schmidt, R. (1980), "Die Ostgrenze von Armenien über Mesopotamien, Syrien bis Arabien”, in G. Neumann, J. Untermann (eds.), Die Sprachen im Römischen Reich der Kaiserzeit. (Bonner Jahrbücher des Rheinischen Landesmuseums in Bonn im Landschaftsverband Rheinland und des Vereins von Altertumsfreunden im Rheinlande 40). Köln, 187-214.

Schmidt, Th., Fleury, P. (2011), Perceptions of the Second Sophistic and its Times. Regards sur la seconde sophistique et son époque, Toronto, Buffalo, London.

Schwartz, J. (1960), Pseudo-Hesiodeia: recherches sur la composition, la diffusion et la disparition ancienne d'oeuvres attribuées à Hésiode, Leiden.

Scott, K. (1936), The Imperial Cult under the Flavians, Stuttgart.

Sealey, R. (1976), A bistory of Greek city-states 700 -338 B. C. Berkeley. 
Seignobos, Ch. (1969), Histoire sincère de la nation française, Paris.

Semerari, L. (2000), Aula Magna Università degli Studi di Bari, Bari.

Sergent, B. (2006), "Sucellus et le tonneau", in Anthropology of the Indo-European World and Material Culture. Proceedings of the 5th International Colloquium of Anthropology of the Indo-European World and Comparative Mythology, Budapest, 61-80.

Serra, J. C. da (1972), Academia Real das Sciencias de Lisboa, II, cap. VII, Lisboa. Sforza, W. C. (1951), “Osservazioni sul 'De nobilitate legum' di Coluccio Salutati”, in E. Castelli (ed.), Umanesimo e Scienza politica (Atti del congresso Internazionale di Studi Umanistici, Roma-Firenze, 1949), Milano.

Shapiro, H.A. (1993), Personification in Greek art: the representation of abstract concepts 600-400 b.C., Zürich.

Shaw, M. H. (1982), “The $\tilde{\eta} \theta$ os of Theseus in 'The Suppliant Women”, Hermes 110. 1: 3-19.

Shorrock, R. (2011), The Myth of Paganism: Nonnus, Dionysus and the World of Late Antiquity, Bristol.

Sigeia, L. (1970), Dialogue de deux jeunes filles sur la vie de retraite (1552), Présenté, traduit et annoté par O. Sauvage (ed.), Paris.

Sillières, P. (1990), Les voies de communication de l'Hispanie méridionale, Paris.

Silva, N. J. E. G. (1964), Humanismo e Direito em Portugal no século XVI, Lisboa.

Simón, I. (2013), Los soportes de la epigrafía paleohispánica. Inscripciones sobre piedra, bronce y cerámica, Zaragoza, Sevilla.

Siniscalco, P. (2004, 5a ed.), Il cammino di Cristo nell'Impero romano, Roma, Bari.

Slavazzi, F. (2006), "Il ciclo di relievi della Kaisersaal del ginnasio di Vedio a Efeso", in Iconografía 2005. Immagini e immaginari dell'antichità classica al mondo moderno, Roma, 235-243

Smyth, A. C. (2011), Polis and Personification in Classical Athenian Art, Leiden.

Snodgrass, A. M. (1977), Archaeology and the rise of the Greek state, Cambridge.

Snodgrass, A. M. (1980), Archaic Greece. The age of experiment, Londres.

Soares, C. (2008), Platão. O Político. Tradução do grego, introdução e notas, Lisboa.

Soares, C. (2014), “Theoria e práxis política em Heródoto”, Cuadernos de Filología Clássica: Estudios griegos e indoeuropeus 24: 57-79.

Soares, N. C. (1994), O príncipe ideal no século XVI e a obra de D. Jerónimo Osório, Coimbra.

Soares, N. C. (2002), "O infante D. Pedro e a cultura portuguesa", Biblos. Revista da Faculdade de Letras 78:107-128. 
Sodano, A. R. (1970), Porphyrii Quaestionum Homericarum Liber I, Napoli.

Solas, J. G. (2008), “Escrito sobre la ciudad”, Pensar la publicidad, II, n. 2: 37-62.

Sordi, M. (1965), Il cristianesino e Roma, Bologna.

Sordi, M. (1984), I cristiani e l'impero romano, Milano.

Soria, A. (1956), Los humanistas de la Corte de Alfonso el Magnánimo (según los epistolarios), Granada.

Sousa, D. A. C. de (1946-1954), Memória dos livros do uso del Rey D. Duarte, in Provas da história genealógica da casa real portuguesa, tomo I, liv. III, Coimbra.

Sousa, R., Fialho, M. C., Haggag, M., Rodrigues, N. S. (2013), Alexandrea ad Aegyptum: The Legacy of Multiculturalism in Antiquity, Lisboa.

Spickermann, W. (1997), "Aspekte einer neuen regionalen Religion und der Prozess der "interpretatio" im römischen Germanien, Rätien und Noricum", in Römische Reichsreligion und Provinzialreligion, Tübingen, 145-167.

Spyridakis, S. (1968), “Zeus is Dead: Euhemerus and Crete”, CJ 63: 337-340.

Stafford, E., Herrin, J. (eds.) (2005), Personification in the Greek World from Antiquity to Byzantium, Burlington.

Statuta capitulorum generalium ordinis Cisterciensis ab anno 1116 ad annum 1786 edidit Josephus M. ${ }^{\text {ia } C a n i v e z ~(1933-1941), ~} 8$ vols., Louvain.

Stefan, A. (2005), "Le titre de filius Augustorum de Maximin et Constantin et la théologie de la tétrarchie", in M.-F. Baslez, F. Prévot (eds.), Prosopographie et histoire religieuse. Actes du colloque tenu en l'Université Paris XII-Val de Marne le 27 Eं 28 octobre 2000, Paris, 329-349

Stefani, G. (1986), "I cippi a botte della provincia Sardinia”, Nuovo bullettino Archeologico Sardo 3: 115-160.

Stefani, G. (1988), "Cippi a botte nella basilica di S. Saturnino a Cagliari”, Quaderni della Soprintendenza archeologica per le province di Cagliari e Oristano 5: 167-175.

Stegmann, A. (1977), "La place de la praxis dans la notion de 'raison d'État' ", in Théorie et pratique politiques à la Renaissance, Paris.

Steinbrecher, M. (1985), Der Delisch-Attischen Seebund und die AthenischSpartanischen Beziehungen in der Kimonischen Ära (478/77-462/1), Berlin.

Stemmer, K (ed.) (1995), Standorte - Kontext und Funktion antiker Skulptur, Berlin.

Sterckx, C. (2008), "Sucellos et le casque d'Hadès", in Philomythia. Mélanges offerts à Alain Moreau, Monts, 223-229.

Stern, J. (1996), Palaephatus. Peri Apiston: On Unbelievable Tales, Wauconda. 
Stern, J. (1999), "Rationalizing Myth: Methods and Motives in Palaephatus" in R. Buxton, R. (ed.), From Myth to Reason? Studies in the Development of Greek Thought, Oxford, 215-222.

Stewart, A. (1990), Greek Sculpture: an exploration, New Haven, Yale.

Storey, I. C. (2003), Eupolis poet of old comedy, Oxford.

Stowe Mead, G. R. (1901), Apollonius of Tyana, the Philosopher-Reformer of the First Century A.D., London.

Strassler, R. B. (ed.) (2007), Landmark Herodotus: The Histories, New York.

Strassler, R.B. (ed.) (2009), Landmark Herodotus: The Histories, New York.

Strootman, R. (2010), "Literature and the Kings", in Clauss, J., Cuypers, M. (eds.), A Companion to Hellenistic Literature, Malden, Oxford, 30-45.

Suberbiola Martínez, J. (1987), Nuevos concilios hispano-romanos de los siglos III y IV. La colección de Elvira, Málaga.

Szabó, Á. (2007), Daciai papság, Budapest.

Szabó, Á. (2008), "Sulla questione dello statuto giuridico dei sacerdoti provinciali durante il principato. Studio preliminare”, Iustum Aequum Salutare 4: 71-81.

Tamerl, I. (2008), Das Holzfass in der römischen Antike mit einer Studie zu Fassfunden in Raetien, Diplomarbeit presso l'Università di Innsbruck, consultabile presso la Universitäts- und Landesbibliothek Innsbruck DG43696.

Tate, J. (1927), “The Beginnings of Greek Allegory”, CR 41.6: 214-215.

Tchernia, A. (1986), Le vin de l'Italie romaine. Essai d'bistoire économique d'après les amphores (BEFAR 261), Rome.

Teive, D. de (1786), Epodos Que Cont'em Sentenças Uteis A todos os Homens, A's quaes se acrescentão Regras para a boa educação de hum principe. Trad. no vulgar em verso solto por Francisco de Andrade (conforme à ed. de Lisboa, 1565), Lisboa, Na Of. Patr. de Francisco Luiz Ameno.

Temporini, H. (1978), Die Frauen am Hofe Trajans. Ein Beitrag zur Stellung der Augustae im Principat, Berlin, New York.

Thomson de Grummond, N. (2006), Etruscan Myth. Sacred History, and Legend, Philadelphia.

Tomlin, R. S. O. (1987), "Was ancient British Celtic ever a written language? Two texts from Roman Bath", Bulletin of the Board of Celtic Studies 34: 18-25.

Topál,J. (1990), “Der Import der sogenannten Moselweinkeramik in Pannonien”, ReiCretActa 27-28: 177-184.

Tortorici, E. (1975), Castra Albana. Forma Italia, Regio I, Roma.

Touchard, J. (1959), Histoire des idées politiques, I. Paris [trad. port. Lisboa, 1970]. 
Tranoy, A. (1981), La Galice romaine, Paris.

Tuchelt, K. (1981), "Zum Problem Kaisareion-Sebasteion. Eine Frage zu den Anfängen des römischen Kaiserkultes”, MDAI, 31 : 167-186.

Ulbert, G. (1959), "Römische Holzfässer aus Regensburg”, Bayerische Vorgeschichtsblätter 24: 6-29.

Ullman, B. L. (1963), The humanism of Coluccio Salutati, Padova.

Ullmann, W. (1980), Radici del Rinascimento (tr. ital.), Roma, Bari.

Unz, R.K. (1985), "The Surplus of the Athenian phoros", GRBS 26: 21-42.

Ureña Prieto, M. H. (2001), Dicionário de Literatura Grega, Lisboa.

Valiño, A. (1999), "La cerveza en las fuentes romanas. Base textual y fijación de su importancia”, AncHistB 13: 60-71.

Van Haeperen, F. (2002), "Le collège pontifical (3ème s. a.C.-4ème s. p.C.)", Études de Philologie, d'Archéologie et d'Histoire Anciennes 39: 11-42.

Varner, E.R. (2004), Mutilation and transformation. Damnatio memoriae and Roman Imperial Portraiture, Leiden, Boston.

Várzeas, M. I. O. (2013), "Callimachus and the New Paths of Myth”, in R. Sousa et alii (coord.) Alexandrea ad Aegyptom: the legacy of multiculturalismo in antiquity. Lisboa.

Velaza, J. (2003), "Epigrafía ibérica emporitana: bases para una reconsideración”, Palaeohispanica 3: 179-192.

Velaza, J. (2003a), "Las inscripciones monetales”, in P. P. Ripollés, M. del M. Llorens, Arse-Saguntum. Historia monetaria de la ciudad y su territorio, Sagunto, 121-148.

Velaza, J. (2009), “Epigrafía y literacy paleohispánica en territorio vascón”, Palaeohispanica 9: 611-622.

Vergerio, P. P. (1934), “Epistolario di Pier Paolo Vergerio”, in L. Smith (ed.), Fonti per la storia d'Italia, vol. 74, Roma, 436-445.

Vierneisel, K., Zanker, P. (1979), Die Bildnisse des Augustus: Herrscherbild und Politik in kaiserlichen Rom, München.

Villar, F., Pedrero, R. (2001), “Arroyo de la Luz III”, Palaeohispanica 1: 235274.

Vinogradov, J. G. (2000), "Heilkundige Eleaten in den Schwarzmeergründungen”, in M. Dreher (ed.), Bürgersinn und staatliche Macht. Festschrift für Wolfgang Schuller zum 65. Geburtstag, Konstanz, 133-149.

Vittinghoff, F. (1951), Römische Kolonisation und Bürgerrechtspolitik unter Caesar und Augustus, Wiesbaden.

Vives, J., Marín, T., Martínez, G. (1963), Concilios visigóticos e hispano-romanos, Madrid, Barcelona. 
Voragine, T. (2004), Legenda Aurea. Apresentação do Cardeal Dom José Saraiva Martins e introdução do Doutor Aníbal Pinto de Castro. Tomo Segundo, Porto.

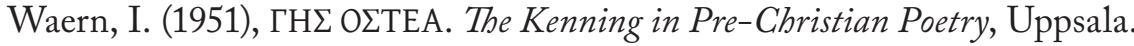

Wallace, M. B., Figueira, T. J. (2010), "Notes on the Island Phoros", ZPE 172: 65-69.

Wallace-Hadrill, A. (2005), "Mutatas formas: The Augustan Transformation of Roman Knowledge", in K. Galinsky (ed.), The Cambridge Companion to the Age of Augustus, Cambridge, 55-84.

Wallinga, H. T. (2005), Xerxes' Greek Adventure. The Naval Perspective, Leiden.

Walter, H. (1993), Ägina: die archäologische Geschichte einer griechischen Insel, München.

Walters, K. R. (1981), "Four Hundred Athenian Ships at Salamis?”, RbM 124: 199-203.

Wankel, H. (1983), "Thukydides 1,74,1 und die Schiffszahlen von Salamis," ZPE 52: 63-66.

Wells, J. (1923), Studies in Herodotus, Oxford.

Wesseling, P. (ed.) (1735), “Itinerarium Antonini Augusti”, Vetera Romanorum Itineraria, Amesterdão.

West, M. L. (1985), The Hesiodic Catalogue of Women: Its Nature, Structure, and Origins, Oxford.

Westrem, S. D. (2001), The Hereford Map. A Transcription and Translation of the Legend with Commentary, Turnhout.

Williams, D. (1987), "Aegina, Aphaia-Tempel XI: the pottery from the second limestone temple and the later history of the sanctuary", $A A$ : 629-680.

Williamson, G. (2004), "Aspects of identity", in C. Howgego, V. Heuchert, A. Burnett (eds.), Coinage and Identity in the Roman Provinces, Oxford, 19-27.

Winiarczyk, M. (2013), The «Sacred History» of Eubemerus of Messene, Berlin.

Witschel, Chr. (1995a), "Römische Tempelkultbilder und Römische Kaiserstatuen als Tempelkultbilder", in K. Stemmer, (ed.), Standorte. Kontext und Funktion antiker Skulptur; Ausstellungskatalog Abgußsammlung, Berlin, 250-265.

Witschel, Chr. (1995b), "Statuen auf römischen Platzanlagen unter besonderer Berücksichtigung von Timgad (Algerien)", in K. Stemmer (ed.), Standorte. Kontext und Funktion antiker Skulptur; Ausstellungskatalog Abgußsammlung, Berlin, 332-358.

Witschel, Chr. (2002), "Zum Problem der Identifizierung von munizipalen Kaiserkultstätten”, Klio 84: 114-124. 
Wlosok, A. (ed.) (1978), Römischer Kaiserkult, Darmstadt.

Wojciechowski, P. (2002), "Il culto di Beleno ad Aquileia romana. Origini, interpretatio Romana e la cosiddetta rinascita celtica", in Gli echi della terra. Presenze celtiche in Friuli. Dati materiali e momenti dell' immaginario. Convegno di studi, Castello di Gorizia, 5 - 7 ottobre 2001, Pisa, 29-35.

Woodard, R. (ed.) (2007), The Cambridge Companion to Greek Mythology, Cambridge.

Woodhead, A. G. (1962), The Greeks in the West. London. (Trad. port., Os Gregos no Ocidente).

Woolf, G. (1996), "Monumental writing and the expansion of the Roman society in the Early Empire", JRS 86: 22-39.

Woolf, G. (2002), "Afterword. How the Latin West was won”, in A. Cookey (ed.), Becoming Roman, writing Latin? Literacy and Epigraphy in the Roman West, JRA Suppl. Ser. 48: 181-188.

Yatromanolakis, Y. (2005), "Poleos erastes. The Greek city as the beloved", in E. Stafford, J. Herrin (eds.), Personification in the Greek World: From Antiquity to Byzantium, London, 267-284.

Young, T. Cuyler (1980), “480/479 B.C. - A Persian Perspective”, Iranica Antiqua 15: 213-39.

Zamora, J. A. (2005), "La práctica de escribir entre los primeros fenicios peninsulares y la introducción de la escritura entre los pueblos paleohispánicos”, Palaeohispanica 5: 155-19.

Zanichelli, G. Z. (2005), "Il mito di Troia nell'immaginario medievale”, in G. Burzacchini (coord.), Troia tra realtà e leggenda, Parma.

Zanker, P. (1983), Provinzielle Kaiserporträts. Zur Rezeption der Selbstdarstellung der Princeps, München.

Zaoli, G. (1912), “Lo Studio bolognese e papa Martino V”, Studi e Memorie per la storia dell'Università di Bologna I - série v. III: 105-188.

Zecchini, G. (ed.) (2015), L'Augusteum di Narona. Atti della Giornata di Studi. Roma 31 maggio 2013, (Centro ricerche e documentazione sull'antichità clàssica, monografie, 37), Roma.

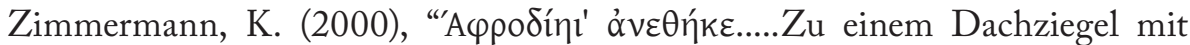
Votivinschrift", in A. Avram, M. Babeş (eds), Olbia, Civilisation grecque et cultures antiques périphériques. Hommages à $P$. Alexandrescu à son $70^{\circ}$ anniversaire, Bucarest, 239-251.

Zurara, G. E. de (1972), Chronica do Conde Dom Pedro de Meneses, II, Lisboa. 